\title{
Uplifting of carbon monoxide from biomass burning and anthropogenic sources to the free troposphere in East Asia
}

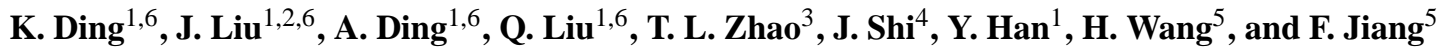 \\ ${ }^{1}$ School of Atmospheric Sciences, Nanjing University, Nanjing, Jiangsu 210093, China \\ ${ }^{2}$ University of Toronto, Toronto, Ontario, M5S 3G3, Canada \\ ${ }^{3}$ Nanjing University of Information Science and Technology, Nanjing, Jiangsu 210044, China \\ ${ }^{4}$ Institute of Remote Sensing Applications, Chinese Academy of Sciences, Beijing 100101, China \\ ${ }^{5}$ International Institute for Earth System Sciences, Nanjing University, Nanjing, Jiangsu 210093, China \\ ${ }^{6}$ Collaborative Innovation Center of Climate Change, Jiangsu 210093, China \\ Correspondence to: J. Liu (jliu@nju.edu.cn)
}

Received: 2 September 2014 - Published in Atmos. Chem. Phys. Discuss.: 12 November 2014

Revised: 22 January 2015 - Accepted: 15 February 2015 - Published: 12 March 2015

\begin{abstract}
East Asia has experienced rapid development with increasing carbon monoxide (CO) emission in the past decades. Therefore, uplifting CO from the boundary layer to the free troposphere in East Asia can have great implications on regional air quality around the world. It can also influence global climate due to the longer lifetime of $\mathrm{CO}$ at higher altitudes. In this study, three cases of high CO episodes in the East China Sea and the Sea of Japan from 2003 to 2005 are examined with spaceborne Measurements of Pollution in the Troposphere (MOPITT) data, in combination with aircraft measurements from the Measurement of Ozone and Water Vapor by Airbus In-Service Aircraft (MOZAIC) program. High CO abundances of 300-550 ppbv are observed in MOZAIC data in the free troposphere during these episodes. These are among the highest $\mathrm{CO}$ abundances documented at these altitudes. On average, such episodes with $\mathrm{CO}$ over $400 \mathrm{ppbv}$ (in the 2003 and 2004 cases) and between 200 and $300 \mathrm{ppbv}$ (in the 2005 case) may occur $2-5$ and $10-20 \%$ in time, respectively, in the respective altitudes over the region. Correspondingly, elevated CO is shown in MOPITT daytime data in the middle to upper troposphere in the 2003 case, in the lower to middle troposphere in the 2004 case, and in the upper troposphere in the 2005 case. Through analyses of the simulations from a chemical transport model GEOS-Chem and a trajectory dispersion model FLEXPART, we found different $\mathrm{CO}$ signatures in the elevated $\mathrm{CO}$ and distinct transport pathways and mechanisms for these cases. In the 2003 case, emissions from large forest fires near Lake Baikal dom-
\end{abstract}

inated the elevated $\mathrm{CO}$, which had been rapidly transported upward by a frontal system from the fire plumes. In the 2004 case, anthropogenic CO from the North China Plain experienced frontal lifting and mostly reached $\sim 700 \mathrm{hPa}$ near the East China Sea, while CO from biomass burning over Indochina experienced orographic lifting, lee-side-troughinduced convection, and frontal lifting through two separate transport pathways, leading to two distinct $\mathrm{CO}$ enhancements around 700 and $300 \mathrm{hPa}$. In the 2005 case, the observed $\mathrm{CO}$ of $\sim 300 \mathrm{ppbv}$ around $300 \mathrm{hPa}$ originated from anthropogenic sources over the Sichuan Basin and the North China Plain and from forest fires over Indochina. The high $\mathrm{CO}$ was transported to such altitudes through strong frontal lifting, interacting with convection and orographic lifting. These cases show that topography affects vertical transport of $\mathrm{CO}$ in East Asia via different ways, including orographic uplifting over the Hengduan Mountains, assisting frontal lifting in the North China Plain, and facilitating convection in the Sichuan Basin. In particular, topography-induced lee-side troughs over Indochina led to strong convection that assisted $\mathrm{CO}$ uplifting to the upper troposphere. This study shows that the new daytime MOPITT near-infrared (NIR) and thermalinfrared (TIR) data (version 5 or above) have enhanced vertical sensitivity in the free troposphere and may help qualitative diagnosis of vertical transport processes in East Asia. 


\section{Introduction}

Carbon monoxide (CO) plays several important roles in the atmosphere. The oxidizing capability, an ability of the atmosphere to cleanse itself, is strongly influenced by the $\mathrm{CO}$ level in the troposphere. $\mathrm{CO}$ near the surface is a major pollutant. Under high $\mathrm{NO}_{\mathrm{x}}$ conditions, $\mathrm{CO}$ is a precursor of ozone, while in low $\mathrm{NO}_{\mathrm{x}}$ air masses, $\mathrm{CO}$ helps ozone destruction (Jacob, 1999; Holloway et al., 2000). As carbon dioxide $\left(\mathrm{CO}_{2}\right)$ is produced in both ozone production and destruction processes (Holloway et al., 2000), CO is linked to the global carbon cycle (Suntharalingam et al., 2004; Yurganov et al., 2008; Nassar et al., 2010) affecting climate change. With a lifetime of weeks to months, $\mathrm{CO}$ is a good tracer tracking transport of pollution. In the purview of these roles, it is important to understand processes influencing the $\mathrm{CO}$ distribution and variability in the atmosphere.

Although the main sources of atmospheric $\mathrm{CO}$ and its mean status are generally understood (Novelli et al., 1998; Jacob, 1999; Holloway et al., 2000), many processes influencing $\mathrm{CO}$ variations at different timescales are not well known. Uplifting CO from the boundary layer to the free troposphere (FT) is such a process, which usually occurs on the synoptic scale that spans hundreds to thousands of kilometers in space and lasts hours to days in time (Daley, 1991). Uplifted CO usually has a longer lifetime and can be transported fast by the upper layer winds over long distances through continents and between hemispheres in the troposphere (Stohl, 2001; Stohl et al., 2002; Damoah et al., 2004). Uplifting air mass from the surface to FT generally takes place by three processes: (1) frontal lifting, (2) orographic lifting, and (3) deep convection (Brown et al., 1984; Banic et al., 1986; Dickerson et al., 1987; Bethan et al., 1998; Pickering et al., 1998; Chung et al., 1999; Donnell et al., 2001; Kowol-Santen et al., 2001; Cooper et al., 2002; Liu et al., 2003; Miyazaki et al., 2003; Chan et al.; 2004; Mari et al., 2004; Li et al., 2005; Liu et al., 2006; Kar et al., 2008; Zhao et al., 2008; Ding et al., 2009; Randel et al., 2010; Chen et al., 2012).

East Asia has experienced rapid development with increasing CO emission in the past decades (Duncan et al., 2007). In addition to impacts on local air quality (Wang et al., 2010), continuing increase in $\mathrm{CO}$ emissions will lead to great impacts on regional air quality and climate of the world (Jaffe et al., 1999; Berntsen et al., 1999; Bertschi et al., 2004) because of an expected upward trend in pollution outflow from the region. East Asia is characterized by its unique and complex meteorology, topography, and land covers. Vertical transport of CO can be modulated by one or more of these conditions or by their interactions. For example, the likelihood of when and where extratropical cyclones are active is closely linked to the locations and frequency of frontal uplifting. Wet and dry convections prevail in different seasons in northern China because of the distinct climatological pattern in precipitation there (Dickerson et al., 2007). The topography there also plays an important role in uplifting of $\mathrm{CO}$ alone and/or interplaying with frontal systems, aiding convection in mountainous regions (Liu et al., 2003; Ding et al., 2009). Recently, Lin et al. (2009) proposed a new mechanism that emphasizes the role of topography-induced lee-side troughs over Indochina in promoting strong convection. A variety of land cover types in East Asia diversifies $\mathrm{CO}$ sources there. In highly populated urban areas, such as those in the North China Plain, anthropogenic emissions are high. Large biomass burning, occurring in areas with abundant vegetation, can generate great amounts of $\mathrm{CO}$ for vertical transport when meteorological conditions become favorable. Two such areas are Southeast Asia and the boreal forested area in Russia (Wotawa et al., 2001; Schultz, 2002; Duncan et al., 2003). So far, our understanding of the impacts of these processes and their interactions on CO uplifting is still rather limited (Dickerson et al., 2007). The objectives of studying vertical transport of CO in East Asia are to better understand the vertical distribution of $\mathrm{CO}$ in the region, to advance the assessment of impacts of long-range transport of Asian $\mathrm{CO}$ on regions downwind, and to help improve simulating this process in atmospheric models on the synoptic scale, eventually leading to more realistic chemical weather forecast in the future (Lawrence et al., 2003).

Due to lack of continuous measurements, most studies on $\mathrm{CO}$ in East Asia are based on observations from periodic field campaigns (Jacob et al., 2003; Tsutsumi et al., 2003; Li et al., 2007; Ding et al., 2009) or simulations by chemical transport models (Berntsen et al., 1999; Bey et al., 2001) or both (Liu et al., 2003). CO measurements from satellites provide unprecedented data revealing $\mathrm{CO}$ variations over East Asia. One of the instruments is the Measurements of Pollution in the Troposphere (MOPITT) (Drummond, 1992; Drummond and Mand, 1996). MOPITT provides data of CO total column and $\mathrm{CO}$ vertical profiles at several altitude levels, which are retrieved using a nonlinear optimal estimation method theoretically based on the observed radiances and their weighting functions, the a priori information, and the retrieval averaging kernels (Rogers, 2000; Deeter et al., 2003). As a result, the MOPITT retrieval at one level can be influenced by $\mathrm{CO}$ at other levels and thus MOPITT vertical resolution is coarse, generally having only 2-3 pieces of independent information vertically in the troposphere. Therefore, MOPITT's vertical sensitivity was an issue with earlier versions of MOPITT data (Jacob et al., 2003). Nevertheless, a few studies (Deeter et al., 2004; Kar et al., 2004, 2006, 2008; Liu et al., 2006) demonstrated MOPITT's vertical sensitivity to some extent. Kar et al. (2004) found Asian summer monsoon plumes in MOPITT $\mathrm{CO}$ data as a strong enhancement of $\mathrm{CO}$ in the upper troposphere over India and southern China. Deeter et al. (2004) illustrated similar distributions of the rain rate and the ratio of MOPITT CO at 350 to at $850 \mathrm{hPa}$ in the tropical eastern Pacific Ocean. Liu et al. (2006) observed large differences (20-40 ppbv) in MOPITT CO at $250 \mathrm{hPa}$ between two cases of vertical transport of $\mathrm{CO}$ and attributed the differences to 
the respective weather systems. Furthermore, the MOPITT data in new versions that use both thermal-infrared (TIR) and near-infrared (NIR) radiances have offered enhanced vertical sensitivity (Worden et al., 2010; Deeter et al., 2012, 2013). Therefore, a detailed examination of MOPITT's vertical sensitivity in East Asia, especially for its ability in detecting vertical transport of high $\mathrm{CO}$ episodes, is desirable.

In this study, three cases of high $\mathrm{CO}$ episodes in East Asia from 2003 to 2005 are examined with MOPITT satellite data, in combination with aircraft measurements from the Measurement of Ozone and Water Vapor by Airbus In-Service Aircraft (MOZAIC) program (Marenco et al., 1998) (see Sects. 2 and 4). The vertical transport mechanisms are analyzed with simulations from a trajectory dispersion model FLEXPART (Stohl et al., 2005) and a chemical transport model GEOS-Chem (Bey et al., 2001), along with other meteorology data and satellite fire data (see Sects. 2 and 4). MOPITT data are analyzed in two ways. First, the vertical sensitivity of MOPITT is evaluated with the coincident MOZAIC data (see Sect. 3) and further illustrated with the three high $\mathrm{CO}$ episodes in comparison with the MOZAIC data (see Sect. 4). Second, the vertical variation in CO captured by MOPITT is used to diagnose vertical transport of CO (see Sect. 4). Discussion on the three cases is synthesized in Sect. 5 and the major conclusions are provided in Sect. 6.

\section{Model and data}

\subsection{Satellite MOPITT CO data}

MOPITT is the first space instrument that targets continuous measurements of tropospheric CO. MOPITT has been onboard of the Terra satellite since 1999, making scientific measurements since March 2000. Terra is flying in a sun synchronous polar orbit with an altitude of $705 \mathrm{~km}$, crossing the equator at $\sim 10: 45$ and 22:45 LT and making 14-15 daytime and nighttime overpasses each day. MOPITT uses a crosstrack scanning method with a swath of 29 pixels (4 pixels in a row), each pixel being $22 \mathrm{~km} \times 22 \mathrm{~km}$. Therefore, with a swath of $\sim 600 \mathrm{~km}$, about one-third of the global area is covered in a day. Additionally, clouds can cause even more gaps in MOPITT daily data. This makes it challenging to use MOPITT data for synoptic studies. It takes 3 days to achieve a near-complete global coverage (Edwards et al., 1999) assuming no blockage from clouds.

MOPITT measures upwelling radiation in two narrow infrared spectral regions for CO retrieval: (1) a TIR band near $4.7 \mu \mathrm{m}$ that has strong carbon monoxide absorption and (2) a NIR band near $2.3 \mu \mathrm{m}$ that has weak CO absorption. MOPITT Version 5 retrieval products are significantly different from earlier products and offer three distinct products depending on application requirements. One of them is a TIR/NIR multispectral product, which has enhanced sensi- tivity to CO in the lower-most troposphere (Worden et al., 2010; Deeter et al., 2012, 2013). Validations and evaluations of MOPITT data in various versions are documented in Emmons et al. (2004), Worden et al. (2010), and Deeter et al. $(2012,2013)$.

In this study, the MOPITT CO profiles (Level 2 data) were first compared with the coincident MOZAIC profiles. Advances of Version 5 (V5, a TIR/NIR multispectral product) from Version 4 (V4, a TIR-only product) data were assessed. Then, the V5 data were used in the case studies, in which MOPITT Level 2 data were gridded horizontally into $0.25^{\circ}$ latitude $\times 0.25^{\circ}$ longitude bins and vertically at the MOPITT resolution of 100 from the surface to $100 \mathrm{hPa}$.

\subsection{Aircraft MOZAIC CO data}

The MOZAIC program was initiated in 1993 by European scientists, aircraft manufacturers, and airlines to collect experimental data (Marenco et al., 1998). MOZAIC consists of automatic and regular measurements of ozone, $\mathrm{CO}$, and water vapor by several long-range passenger airliners flying all over the world. The aim is to build a large database of measurements to allow studies of chemical and physical processes in the atmosphere.

In comparing MOPITT with MOZAIC CO data, coincident MOPITT and MOZAIC data from 2003 to 2005 were screened within a radius of $1.5^{\circ}$ and within a $4 \mathrm{~h}$ period. The radius of $1.5^{\circ}$ was applied to selected MOZAIC profiles at $500 \mathrm{hPa}$ and the MOZAIC slant path was included in the radius. MOZAIC profile was smoothed by applying the MOPITT averaging kernels and the a priori profile for the co-located retrieved MOPITT profile to account for the bias introduced by the averaging kernels and the a priori. Therefore, the smoothed MOZAIC CO profile $\hat{\boldsymbol{x}}^{\text {MOZAIC }}$ is derived by (Rogers, 2000)

$\hat{\boldsymbol{x}}^{\text {MOZAIC }}=\boldsymbol{x}^{\text {MOPITT }}+\mathbf{A}\left(\boldsymbol{x}^{\text {MOZAIC }}-\boldsymbol{x}_{\mathrm{a}}^{\text {MOPITT }}\right)$,

where $\mathbf{A}=\delta \hat{\boldsymbol{x}} / \delta \boldsymbol{x}$ is the MOPITT averaging kernel matrix which describes the sensitivity of the MOPITT CO estimate to the true profile of $\mathrm{CO}, \boldsymbol{x}^{\text {MOZAIC }}$ is the MOZAIC CO profile, which has been mapped to the MOPITT pressure grid. The quantity $\boldsymbol{x}_{\mathrm{a}}^{\text {MOPITT }}$ is the MOPITT a priori, which is based on CO simulations from the MOZART model (Emmons et al., 2004).

The MOZAIC measurements usually extend from the surface to $\sim 250 \mathrm{hPa}$. When validating MOPITT data using Eq. (1), CO mixing ratios above $300 \mathrm{hPa}$ was supplemented with CO from the GEOS-Chem chemical transport model (see Sect. 2.6) on the same location and day, similar to the treatments by Worden et al. (2010), who used the MOZART climatology simulations. Because $\mathrm{CO}$ above $250 \mathrm{hPa}$ is lower than that in the middle and lower troposphere, the bias due to this treatment is expected to be low. 


\subsection{MODIS fire count data}

The Moderate-resolution Imaging Spectroradiometer (MODIS) is the type of instrument which has been onboard of the Terra (EOS AM) satellite since 1999 and on the Aqua (EOS PM) satellite since 2002. The MODIS fire products include a validated daily global active fire product (MOD14 Terra and MYD14 Aqua) (Justice et al., 2002), generated using a global active fire detection algorithm that uses a multispectral contextual approach to exploit the strong emission of mid-infrared radiation from fires allowing subpixel fire detection (Giglio et al., 2003). The horizontal resolution is $1 \mathrm{~km}$. The fire data are acquired from the Fire Information for Resource Management System (FIRMS) (Davies et al., 2009).

\subsection{NCEP FNL meteorological data}

The National Centers for Environmental Prediction (NCEP) final (FNL) global tropospheric analyses are on $1^{\circ} \times 1^{\circ}$ grids every $6 \mathrm{~h}$ (http://rda.ucar.edu/datasets/ds083.2/). Parameters in FNL include surface pressure, sea level pressure, geopotential height, temperature, sea surface temperature, potential temperature, relative humidity $(\mathrm{RH})$, precipitable water, $u$ and $v$ winds, and vertical motion, available on the surface, at 26 levels from 1000 to $10 \mathrm{hPa}$, the tropopause, the boundary layer, and a few others. In addition to driving FLEXPART (see Sect. 2.5), the FNL data are used to analyze the meteorological conditions including the surface pressure, wind fields, and development of a cyclone. The data are generated from the global data assimilation system (GDAS).

\subsection{The FLEXPART trajectory model}

To diagnose the transport processes and trace $\mathrm{CO}$ sources, we used the FLEXPART model (Stohl et al., 2005), which is a Lagrangian Particle Dispersion Model developed at the Norwegian Institute for Air Research in the Department of Atmospheric and Climate Research. FLEXPART can be driven by meteorological input data generated from a variety of global and regional models. In this study, the simulations were driven by the NCEP FNL data. This model has been extensively validated (Stohl et al., 1998; Cristofanelli et al., 2003) and widely used in studies of the influence of various meteorological processes on pollution transport (Cooper et al., 2004, 2005, 2006; Hocking et al., 2007; Ding et al., 2009; Barret et al., 2011; He et al., 2011; Chen et al., 2012). In running FLEXPART, a large number of particles are released from defined locations (latitude, longitude, and altitude) at a time. Backward or forward trajectories of the particles are recorded in latitude $\left({ }^{\circ}\right)$, longitude $\left({ }^{\circ}\right)$, and altitude $(\mathrm{km})$ every hour.

\subsection{The GEOS-Chem chemical transport model}

GEOS-Chem is a global three-dimensional chemical transport model (http://geos-chem.org). The model contains detailed description of tropospheric $\mathrm{O}_{3}-\mathrm{NO}_{\mathrm{x}}$-hydrocarbon chemistry, including the radiative and heterogeneous effects of aerosols. It is driven by assimilated meteorological observations from the National Aeronautics and Space Administration (NASA) Goddard Earth Observing System (GEOS) from the Global Modeling and Assimilation Office (GMAO). In this study, GEOS-Chem version v9-1-3 was employed and executed in the full chemistry mode, which is driven by GEOS meteorology with temporal resolution of $6 \mathrm{~h}(3 \mathrm{~h}$ for surface meteorological variables), with a horizontal resolution of $2^{\circ}$ latitude by $2.5^{\circ}$ longitude and 47 vertical levels, including $\sim 35$ levels in the troposphere from 1000 to $100 \mathrm{hPa}$.

GEOS-Chem uses anthropogenic emissions from the Emissions Database for Global Atmospheric Research (EDGAR) global inventory (Olivier and Berdowski, 2001), which are updated with regional inventories, including the emission inventory in Asia (Streets et al., 2006; Zhang et al., 2009). The biomass burning emissions are from the Global Fire Emissions Data (GFEDv3) monthly inventories (van der Werf et al., 2010) and biogenic volatile organic compound (VOC) emissions are taken from the Model of Emissions of Gases and Aerosols from Nature (MEGAN) global inventory. Emissions from other natural sources (e.g., lightning, volcanoes) are also included.

The model has been extensively evaluated and used in studies of atmospheric chemistry and pollution transport (Bey et al., 2001; Heald et al., 2003; Liu et al., 2003, 2006; Zhang et al., 2006; Jones et al., 2009; Nassar et al., 2009; Kopacz et al., 2010; Jiang et al., 2011). GEOS-Chem can generally describe $\mathrm{CO}$ variability in the troposphere but somewhat underestimate the observations in the northern mid-latitudes possibly due to biases in the $\mathrm{CO}$ inventory or numerical diffusion in the model or both (Heald et al., 2003; Duncan et al., 2007; Nassar et al., 2009; Kopacz et al., 2010).

\section{Comparison between MOPITT and MOZAIC CO profiles}

MOPITT's vertical sensitivity can be described in terms of the averaging kernels (see Eq. 1) and the degree of freedom for signal (DFS). The averaging kernel matrix indicates the sensitivity of the MOPITT CO estimate to the true $\mathrm{CO}$ profile, with I (identity matrix) being the best, when true $\mathrm{CO}$ profiles are retrieved, and 0 being the worst, when MOPITT retrievals just take the a priori. In reality, the average kernel matrix is less than $\mathbf{I}$, implying some contribution of $\mathrm{CO}$ from other levels to the retrieved level so that the $\mathrm{CO}$ vertical structure cannot be fully resolved. DFS gives the number of independent pieces of information available vertically in the measurements and it is the sum of the diagonal elements of 
the averaging kernel matrix (Rogers, 2000). Figure 1 shows a yearly mean of DFS for daytime and nighttime, respectively, in East Asia for the V5 TIR/NIR data, indicating substantial increases in DFS compared to earlier MOPITT versions (Worden et al., 2010; Deeter et al., 2012). The daytime annual mean DFS in East Asia (Fig. 1a) ranges from 0.5 to 2.7, usually decreasing with latitude, similar to its distribution in other regions and on the global scale (Deeter et al., 2004; Worden et al., 2010). In the same latitudinal zones, the DFS is higher over land than over ocean. The daytime annual mean DFS is high in the Sichuan Basin, the eastern part of mainland China, the Indochina peninsula, and the Indian subcontinent. Over the mountain or valley regions, DFS is low, such as above the Tibetan Plateau. The stars indicate the cities where MOZAIC vertical measurements are available for validation of MOPITT data. The annual mean DFS is $1.65,1.51,1.60$, and 1.64, respectively, in an area of $1^{\circ} \times 1^{\circ}$ around Beijing, Narita, Shanghai, and Hong Kong, with a maximum of $1.98,1.64,1.81$, and 1.74 for the cities, respectively. The nighttime DFS values (Fig. 1b) are lower (from 0.5 to 1.5 ) than the daytime values, similar to that in Deeter et al. (2004) for an earlier MOPITT version. Spatially, nighttime DFS is high over regions where the daytime DFS is also high.

The general patterns of MOPITT averaging kernels have been documented (Pan et al., 1998; Emmons et al., 2004; Deeter et al., 2003, 2004, 2012; Kar et al., 2008; Worden et al., 2010). For V5 MOPITT data, the averaging kernels at the four cities are similar to these in Worden et al. (2010, in their Fig. 7). The difference in the averaging kernels between V4 and V5 can be as large as 0.14 in the surface and lower troposphere and as 0.10 in the upper troposphere (not shown).

Figure 2 shows the relative bias between MOPITT and the smoothed MOZAIC ( $\left.\hat{\boldsymbol{x}}^{\text {MOZAIC }}\right)$ profiles (see Eq. 1), which is also referred to as the "MOPITT estimate of in situ" in Worden et al. (2010) and the "transferred profile" in Emmons et al. (2004). For V5 data (in red), the mean bias is within $\pm 20 \%$ for all the cities. In all the altitude levels, the bias is the smallest (close to zero) around $500-400 \mathrm{hPa}$ and increases upward and downward. The bias is mostly positive above $500-400 \mathrm{hPa}$, while below $500-400 \mathrm{hPa}$, it is positive at Beijing and Narita but negative at Shanghai and Hong Kong. Whether the sign change is related to the change in the geographic location (Shanghai and Hong Kong are both coastal cities) can be a subject for further study. The V4 data (in green) also show the smallest bias in the middle troposphere. In the lower troposphere, the bias in V5 is reduced by 5-10\% at Beijing and Narita. At Shanghai, the bias changes from positive in V4 to negative in V5, with a smaller magnitude, while at Hong Kong, the negative bias in V4 becomes larger in magnitude in V5. In the upper troposphere above $500-400 \mathrm{hPa}$, the bias in V5 at Beijing, Narita, and Shanghai changes to positive, with a magnitude similar to or larger than that in V4. At Hong Kong, the bias in V5 remains positive but the magnitude is enlarged. Deeter et al. (2013) com-
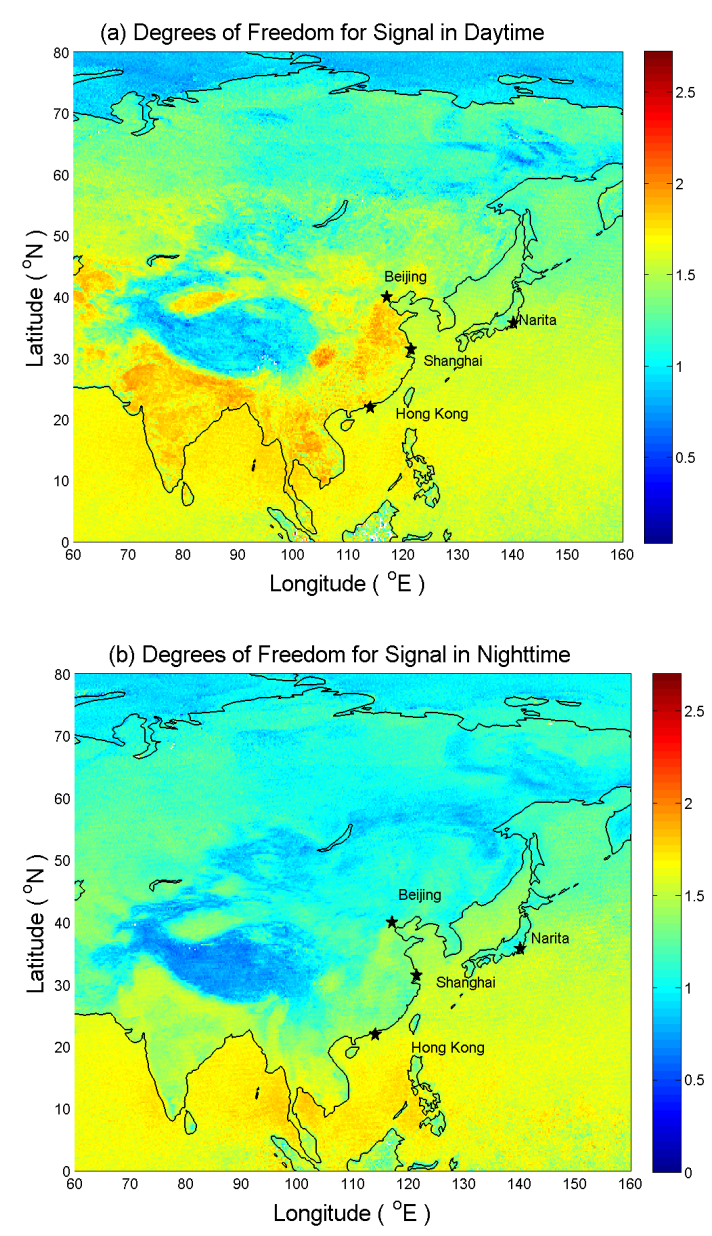

Figure 1. The degree of freedom for signal (DFS) of the MOPITT V5 TIR/NIR data over East Asia, averaged for 2005 during (a) daytime and (b) nighttime. Locations of four cities with MOZAIC CO measurements are indicated as stars. Note that the MOZAIC CO data from Narita also include a small portion of measurements from its surrounding cities at Osaka and Nagoya.

pared MOPITT data with the National Oceanic and Atmospheric Administration (NOAA) aircraft measurements over North America and data from the (High-performance Instrumented Airborne Platform for Environmental Research) HIAPER Pole-to-Pole Observations (HIPPO) field campaign data (Wofsy et al., 2011). They found a positive bias in MOPITT V5 TIR/NIR data at $400(4 \%)$ and $200 \mathrm{hPa}(14 \%)$. They also showed a latitude-dependent positive bias in the northern hemispherical upper troposphere in MOPITT V3 and V4 data. This study suggests an overall positive bias, agreeing with Deeter et al. (2013) in magnitude and sign, in MOPITT V5 data for the upper troposphere. As a comparison, we also validated MOPITT data in other cities around the globe and found that the mean bias in Europe or the United States is lower than that in East Asia, especially in the surface layer (not shown). 

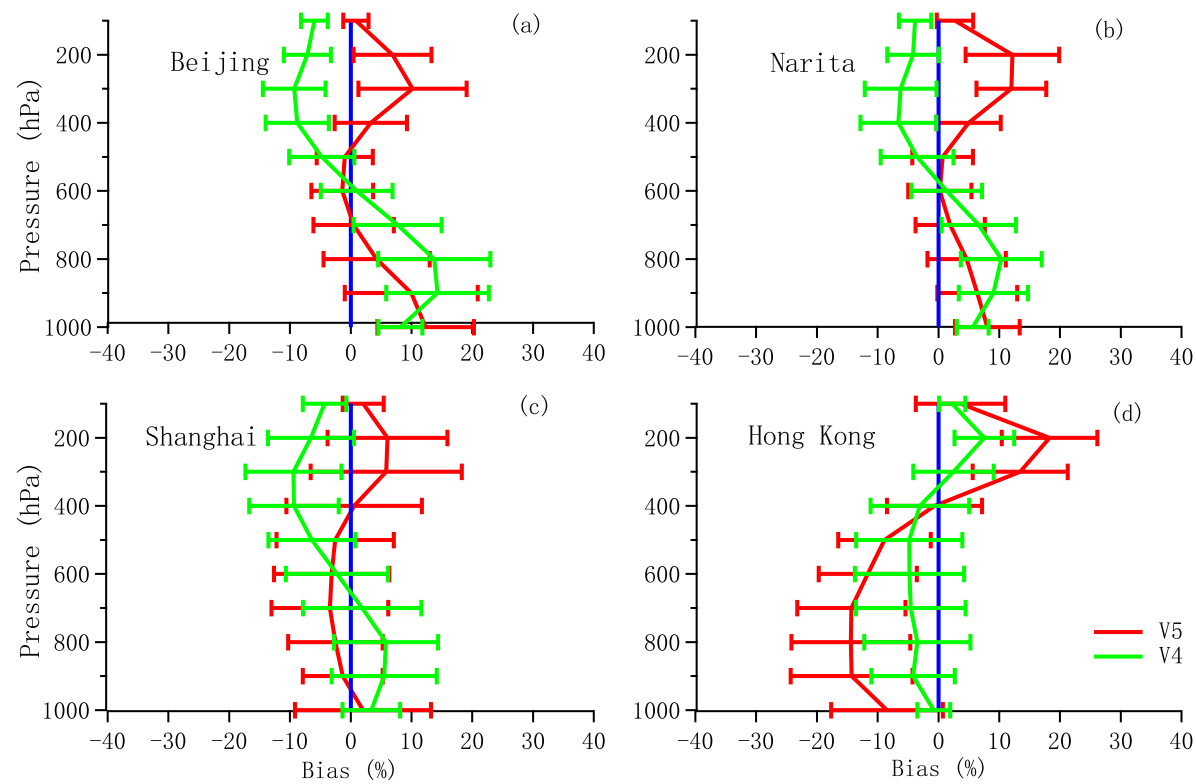

Figure 2. Relative bias of CO profiles (in \%) between MOPITT and MOZAIC data (smoothed with the MOPITT averaging kernels; see Eq. 1) from 2003 to 2005 at Beijing, Narita, Shanghai, and Hong Kong for MOPITT V4 and V5 data. The number of profiles for the comparison is 18, 23, 11, and 15, respectively, at Beijing, Narita, Shanghai, and Hong Kong. The error bars indicate the interquartile range of the mean.
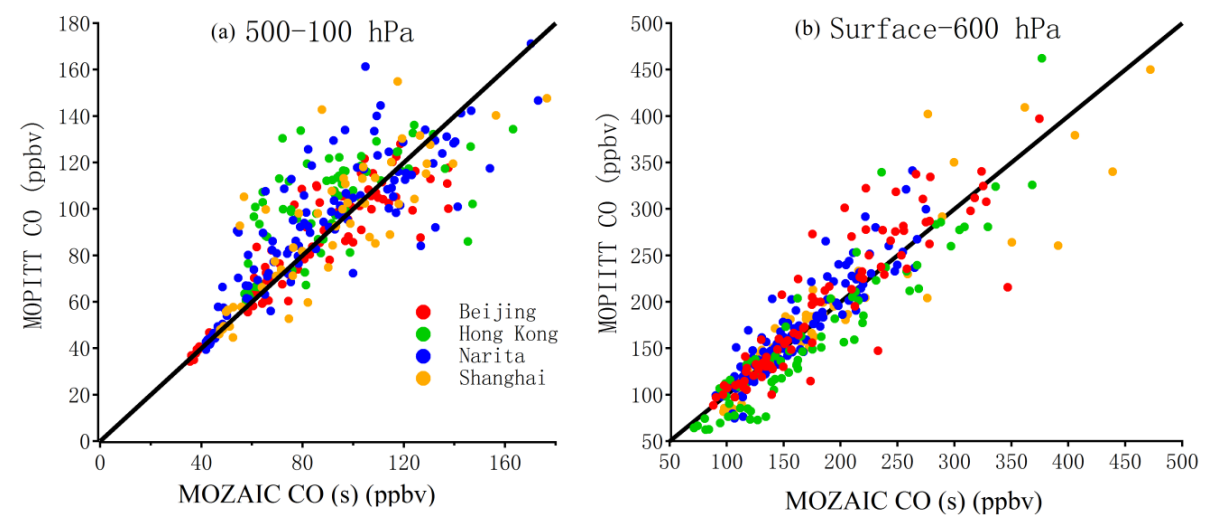

Figure 3. Correlation between MOPITT and MOZAIC data (smoothed with the MOPITT averaging kernels, see Eq. 1) from 2003 to 2005 at Beijing, Narita, Shanghai, and Hong Kong (a) from the middle to upper troposphere and (b) from the surface to the middle troposphere.

The correlation between MOPITT and smoothed MOZAIC data is shown in Fig. 3. From 500 to $100 \mathrm{hPa}$, the correlation coefficient between the two data sets is 0.92 , 0.86, 0.83, 0.68 at Beijing, Narita, Shanghai, and Hong Kong, respectively (Fig. 3a), while from the surface to $600 \mathrm{hPa}$, the correlation becomes stronger, being 0.90,0.92, 0.92, 0.94 at Beijing, Narita, Shanghai, and Hong Kong, respectively (Fig. 3b). The correlation coefficient between the two data is best in the middle troposphere $(500-400 \mathrm{hPa}$, not shown).

\section{Uplifting of $\mathrm{CO}$ to the free troposphere}

Daily MOPITT and MOZAIC data from 2003 to 2005 were screened to find cases of high $\mathrm{CO}$ episodes observed by both MOPITT and MOZAIC at the same location and time. We found three cases of high CO in MOPITT data with close-by MOZAIC measurements, while it was hard to find such high $\mathrm{CO}$ episodes with exact coincident MOPITT and MOZAIC observations because of large gaps in MOPITT data and limited aircraft sampling coverages. In the three cases, high CO concentrations up to $300-500 \mathrm{ppbv}$ were observed by MOZAIC in the free troposphere from 750 to $250 \mathrm{hPa}$.

In the following, we provide detailed analyses of each case, ordered by year of occurrence (Table 1). The cases oc- 
Table 1. Characterization of the three cases.

\begin{tabular}{llll}
\hline Case & 2003 & 2004 & 2005 \\
\hline Date & 6 June 2003 & 18 March 2004 & 10 April 2005 \\
\hline $\begin{array}{l}\text { Maximum CO (ppbv) } \\
\text { in MOZAIC profiles }\end{array}$ & $\sim 550$ & $\sim 500$ & $\sim 300$ \\
\hline $\begin{array}{l}\text { CO peak height (hPa) } \\
\text { in MOZAIC profiles }\end{array}$ & $500-350$ & $750-550$ & $350-250$ \\
\hline $\begin{array}{l}\text { Maximum CO (ppbv) } \\
\text { in MOPITT images }\end{array}$ & $300-400$ & $200-250$ & $150-250$ \\
\hline $\begin{array}{l}\text { CO peak height (hPa) } \\
\text { in MOPITT images }\end{array}$ & $650-300$ & & $400-250$ \\
\hline $\begin{array}{l}\text { Peak CO area } \\
\text { in MOPITT images }\end{array}$ & $35-55^{\circ} \mathrm{N}, 125-145^{\circ} \mathrm{E}$ & $20-32^{\circ} \mathrm{N}, 125-135^{\circ} \mathrm{E}$ & $32-37^{\circ} \mathrm{N}, 130-140^{\circ} \mathrm{E}$ \\
\hline $\begin{array}{l}\text { Major CO sources } \\
\text { Large fires in Russia } \\
\text { near Lake Baikal }\end{array}$ & $\begin{array}{l}\text { Fires in the Indochina peninsula, } \\
\text { anthropogenic emissions in the } \\
\text { North China Plain }\end{array}$ & $\begin{array}{l}\text { Fires in the Indochina peninsula, } \\
\text { anthropogenic emissions in the } \\
\text { North China Plain and the Sichuan Basin }\end{array}$ \\
\hline $\begin{array}{l}\text { Vertical transport } \\
\text { mechanism }\end{array}$ & $\begin{array}{l}\text { Frontal lifting } \\
\begin{array}{l}\text { Outflow } \\
\text { Convection, frontal lifting, }\end{array}\end{array}$ & $\begin{array}{l}\text { Convection, frontal lifting, } \\
\text { and orographic lifting }\end{array}$ \\
\hline
\end{tabular}

curred over the East China Sea or the Sea of Japan or both. High CO was shown in MOPITT daytime data in the middle to upper troposphere in case 2003, in the lower to middle troposphere in case 2004, and in the upper troposphere in case 2005. The MOPITT and MOZAIC observations for the three cases are shown in Figs. 4-6, followed by analyses for each case with FLEXPART and GEOS-Chem simulations, in combination with MODIS fire data and NCEP FNL meteorological data. The cases occurred in spring and summer when cyclone activities are strong in East Asia (Chen et al., 1991; Yue and Wang, 2008). The main CO sources are identified as biomass burning or a combination of biomass burning and anthropogenic origins. The outflow of the high $\mathrm{CO}$ episodes finally reached the boundary layer at the west coast of the United States and Canada.

\subsection{Case study I: 6 June 2003}

On 6 June 2003, a large area $(\sim 400 \mathrm{~km} \times 1500 \mathrm{~km})$ of high $\mathrm{CO}$ up to $350 \mathrm{ppbv}$ appeared in the MOPITT image over the Sea of Japan and the nearby continent in the middle to high troposphere (Fig. 4a). In Fig. 5a, the MOPITT CO profile averaged over the boxed area in Fig. 4a shows a broad enhancement from the monthly profile between 650 and $300 \mathrm{hPa}$, with peak $\mathrm{CO}$ abundances of $\sim 300 \mathrm{ppbv}$ around $550 \mathrm{hPa}$. The location and shape of the box was selected to ensure enough MOPITT samplings (>30) at the closest upwind direction of MOZAIC measurements (the same for Fig. $4 b$ and c). The large difference between the MOPITT a priori and the measurements over these altitudes in- dicates MOPITT's capability of detecting pollution episodes with some degree of vertical sensitivity. The vertical sensitivity is demonstrated through (1) the strongest CO source among the three cases was shown as the largest magnitude (200-250 ppbv) of elevated CO from the a priori, (2) the altitude with the maximum $\mathrm{CO}$ enhancement was detected around the middle troposphere, in contrast to the other two cases which show the maximum in the lower-middle and upper troposphere, respectively, and (3) the elevated $\mathrm{CO}$ was over a broad range of altitudes as the vertical resolution of MOPITT is rather coarse, i.e., the annual mean DFS maximizes about 2.5 (Fig. 1). This CO peak was not shown in the MOPITT monthly mean profile, reflecting the episodic nature of this event. The high $\mathrm{CO}$ episode was also detected by a near-by MOZAIC measurement (Fig. 5b). A layer of elevated $\mathrm{CO}$ is apparent between 500 and $350 \mathrm{hPa}$, with a $\mathrm{CO}$ peak up to $\sim 550 \mathrm{ppbv}$ around $400 \mathrm{hPa}$. In addition, the MOZAIC relative humidity and ozone profiles are shown in Fig. 5b. Around the altitudes of $\mathrm{CO}$ buildup, elevated humidity followed the $\mathrm{CO}$ profile, while ozone also showed some enhancement.

A latitude-altitude cross section from MOPITT is shown in Fig. 6a. It is the average between two blue dashed lines in Fig. 4a. The arrows represent the winds in the meridional and vertical directions and the contour represents the zonal wind speed. Consistent with Fig. 4a, high CO up to 350 ppbv appeared in the middle to upper troposphere between 35 and $50^{\circ} \mathrm{N}$. 
(a) $\mathrm{CO}$ (ppbv) and Wind Field at $500 \mathrm{hPa}, 06$ June 2003
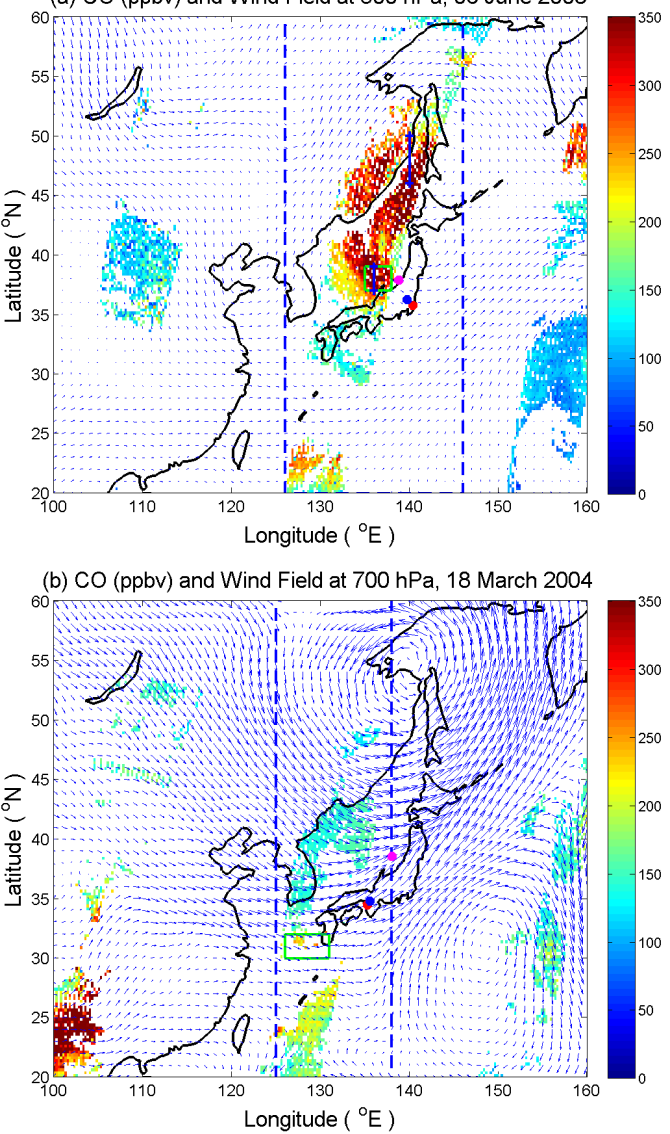

(c) CO (ppbv) and Wind Field at $300 \mathrm{hPa}, 10$ April 2005

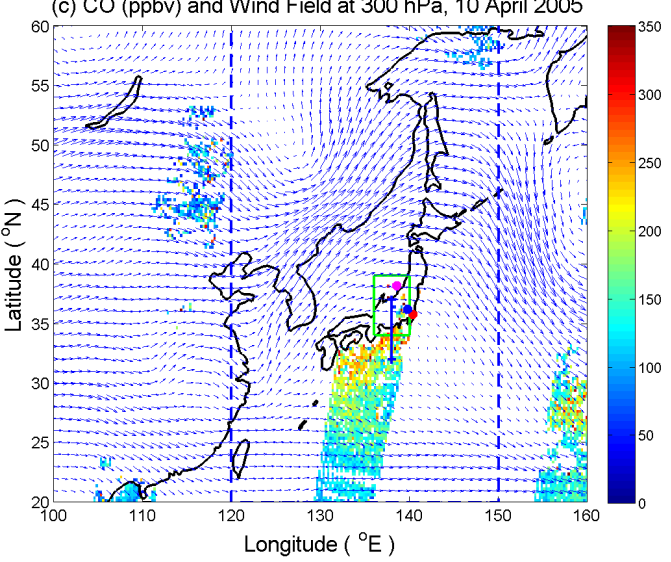

Figure 4. MOPITT CO mixing ratio (ppbv, in color) (a) on 6 June 2003 at $500 \mathrm{hPa}$, (b) on $18 \mathrm{March} 2004$ at $700 \mathrm{hPa}$, and (c) on 10 April, 2005 at $300 \mathrm{hPa}$. All are overlaid with horizontal winds (in arrows) at the same altitude. In each subfigure, the locations of MOZAIC data at 900,600 , and $300 \mathrm{hPa}$ are indicated as red, blue and pink dots, respectively. The box indicates an area over which mean MOPITT CO profile is taken and displayed in Fig. 5. The box is selected to ensure enough MOPITT samplings at the closest upwind direction of MOZAIC measurements. The two blue dashed lines define the longitudinal zone, over which the $\mathrm{CO}$ abundances were averaged and shown in Fig. 6. The solid blue bars in Fig. 4a and $\mathrm{c}$ indicate the locations where particles were released and backward trajectories were simulated using FLEXPART (see text for detail).
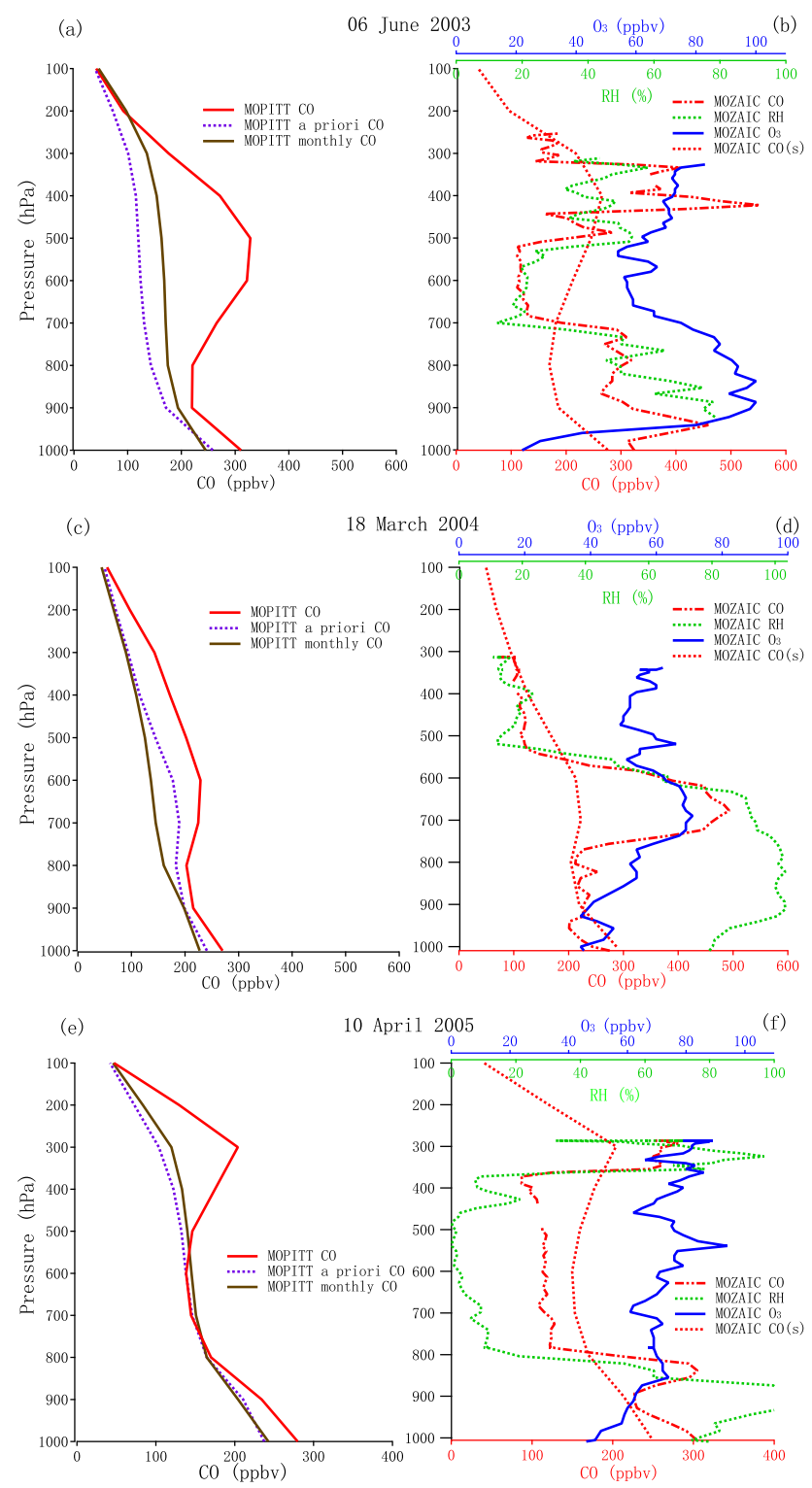

Figure 5. Profiles of MOPITT CO and the a priori, averaged over the corresponding boxed area in Fig. 4 on (a) 6 June 2003, (c) 18 March 2004, and (e) 10 April 2005, respectively, along with their monthly mean MOPITT CO profile over the same area. The corresponding MOZAIC CO profiles (along the dots in Fig. 4) on the same day are shown in (b), (d), and (f), respectively. The corresponding MOZAIC ozone and relative humidity profiles are also shown in (b), (d), and (f). Note that the smoothed MOZAIC CO profiles (MOZAIC CO(s)) were calculated using the averaging kernels and the a priori in the boxed area in each case (see Sect. 5 for discussion).

To trace down the CO source, backward trajectories of the air particles were simulated using FLEXPART after releasing 30000 and 7000 particles, respectively, from the locations of the large and small boxed areas in Fig. 6a (the same as the blue bars in Fig. 4a) on 6 June 2003 when CO 

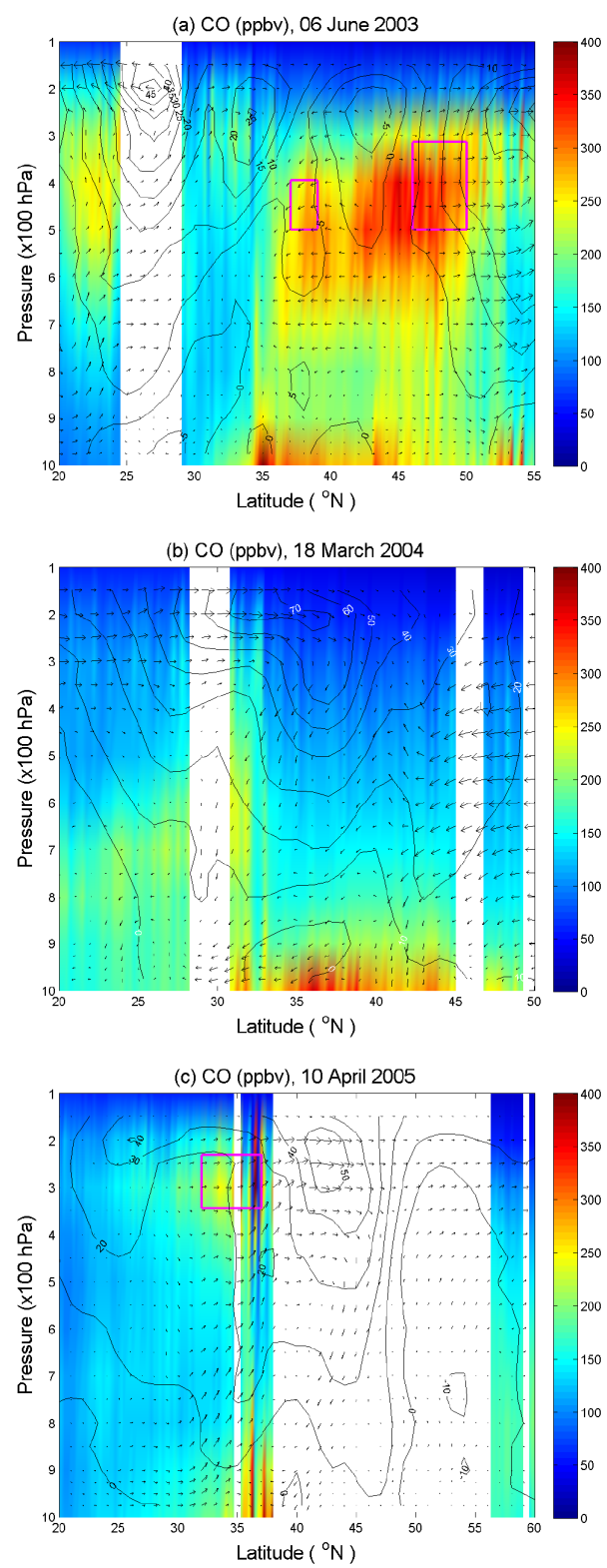

Figure 6. A latitude-altitude cross section of MOPITT CO averaged between the two blue dashed lines in Fig. 4 on (a) 6 June 2003, (b) 18 March 2004, and (c) 10 April 2005. The contour lines indicate $U$ wind speed $\left(\mathrm{m} \mathrm{s}^{-1}\right)$. Vectors are for wind directions in $V$ and $W$. For a better illustration, $W$ is enlarged by a factor of 100 . The pink box(es) in (a) and (c) indicate the locations where particles were released and backward trajectories were simulated using FLEXPART (see text for detail).

was high in the MOPITT data. Because $\mathrm{CO}$ has a relatively long lifetime (weeks to months), it is assumed that $\mathrm{CO}$ is not removed in the backward trajectories. Figure 7 shows the distribution of particle concentration between 6.25 and $10.25(\sim 500-250 \mathrm{hPa}$, Fig. 7a) and between 0 and $3.25 \mathrm{~km}$ ( $\sim 1000-650 \mathrm{hPa}$, Fig. 7b). The contour lines indicate the geopotential height at $850 \mathrm{hPa}$ at 12:00 UTC on 3 June 2003
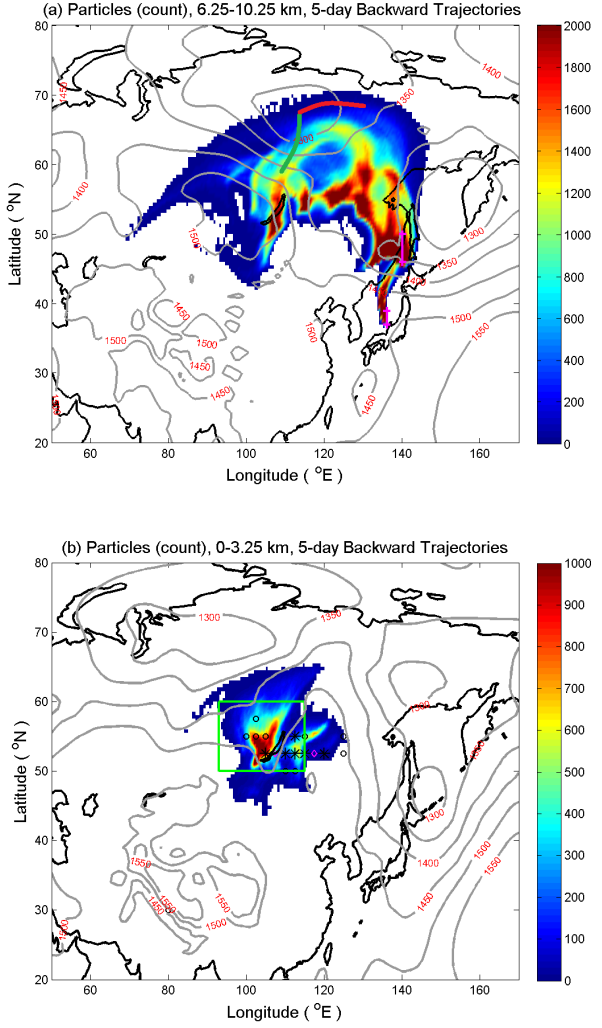

Figure 7. (a) Particle distribution between 6.25 and $10.25 \mathrm{~km}$ ( 550-250 hPa) during 1-6 June 2003. The particles were released from two locations (in pink lines) around $400 \mathrm{hPa}$ (also see Figs. $4 \mathrm{a}$ and 6a) on 6 June 2003 and backward trajectories were calculated. The contour lines are the geopotential heights at $850 \mathrm{hPa}$ on 3 June 2003. A cold front and a warm front are indicated by green and red lines, respectively. (b) the same as (a), but between 0 and $3.5 \mathrm{~km}$. The contour lines are the geopotential heights at $850 \mathrm{hPa}$ on 2 June 2003. The circles, diamonds, and stars denote daily mean fire counts of $20-100,100-300$, and $300-500$ per $2.5^{\circ} \times 2.5^{\circ}$ grid area, respectively, from 31 May to 6 June.

(Fig. 7a) and at 00:00 UTC on 2 June 2003 (Fig. 7b), respectively. The locations of large forest fires near Lake Baikal from MODIS fire data are indicated in Fig. $7 \mathrm{~b}$ by the stars, diamonds, and circles, with fire counts of 20-100, 100-300, and $300-500$ per $2.5^{\circ} \times 2.5^{\circ}$ grid area, respectively, averaged daily from 31 May to 6 June. The high particle counts between 0 and $3 \mathrm{~km}$ in the vicinity of Lake Baikal match well with the location of fire counts (Fig. 7b). On 3 June 2013, there was a cyclone with a cold front (Fig. 7a) that rapidly lifted the $\mathrm{CO}$ originated from the fires along the warm conveyer belt (WCB) to the upper level. The particle distribution in the upper troposphere shows the transport pathway of the particles to the Sea of Japan. To further illustrate this, particles were released from the fire region near Lake Baikal (93$115^{\circ} \mathrm{E}, 50-60^{\circ} \mathrm{N}, 0-3 \mathrm{~km}$, following Lavoué et al. (2000), who found an average injection height of Siberian fires of $\sim 3 \mathrm{~km}$ ). Forward trajectories were simulated and the resul- 


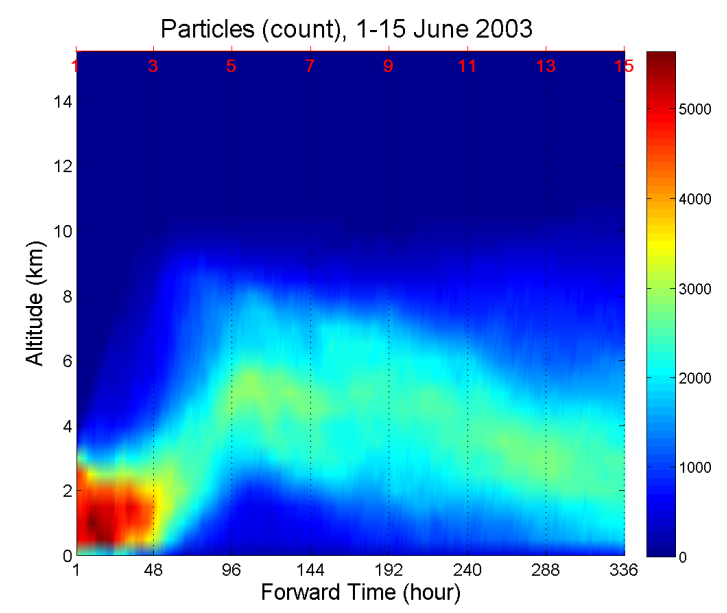

Figure 8. Vertical distribution of particles, varying with time from 1 June 2003 at 00:00 UTC to 15 June 2003 at 00:00 UTC. The particles were released from fire regions in Fig. $7 \mathrm{~b}$ from the surface to $3 \mathrm{~km}$ on 1 June 2003 and forward trajectories were calculated (14 days). The forward time (in $\mathrm{h}$ ) and date (in June) are indicated in the $x$ axis on the bottom and the top, respectively.

tant vertical distribution of the particles, varying with time during 1-15 June 2003, is shown in Fig. 8. The released particles from the fires traveled along the isobars to northeast of Lake Baikal from 1 June to 3 June 2003 and then the particles were lifted to the upper layers $(2-5 \mathrm{~km})$ starting on 3 June at 12:00 LT (in 60-70 h) (Fig. 8). Then, the particles were transported further upward and eastward. On 6 June (in 120-140 h), a large amount of particles appeared in a layer of 3-8 km (Figs. 8 and $4 \mathrm{a}$ ). The altitudes with high particle concentrations agree well the MOPITT data between 650 and $350 \mathrm{hPa}$ (Figs. $4 \mathrm{a}$ and 6a).

It is the cyclone with a front northeast of Lake Baikal that transported the $\mathrm{CO}$ up along the WCB (Figs. 7a and 8). Figure $5 \mathrm{~b}$ shows that the relative humidity reached about $65 \%$ in the MOZAIC measurement, suggesting the air mass indeed came from a WCB (Cooper et al., 2002). The MOZAIC ozone profile also shows elevated ozone at the same altitudes but the shape does not exactly follow the ones of $\mathrm{CO}$ and humidity, implying complexity of chemical processes involved. The polluted air reached as high as $9 \mathrm{~km}$ although most particles remained at heights of about 3-8 km (Fig. 8). After being lifted to higher altitudes, the polluted air was transported by strong westerlies over long distances. Figure 8 shows that the particles were further transported to the east and sink slowly after 7 June. Around 14 June 2003, the particles reached the east coast of Canada $(0-5 \mathrm{~km})$. The satellite MODIS data show a large number of hot spots near Lake Baikal in May and June 2003. Earlier studies have shown that forest fires in Asia can impact air quality in North America (Jaffe et al., 2004; Liang et al., 2004; Oltmans et al., 2010). This case illustrates again the role that WCBs played in the intercontinental transport of pollution for such high $\mathrm{CO}$. Notice that the
FLEXPART simulation was made by using the FNL meteorological data, which may not have considered the buoyancy force due to fires. Such buoyancy force can lift CO plumes even faster and higher.

Our analyses are consistent with Nédélec et al. (2005), who examined 320 MOZAIC flight routes from Europe to Asia in 2003 and reported the observations of high CO up to $800 \mathrm{ppbv}$ above $8 \mathrm{~km}(\sim 350 \mathrm{hPa})$ on 3 and 4 June 2003 around $57^{\circ} \mathrm{N}$ (northeast of Lake Baikal). With different data sets, i.e., along-track scanning radiometer (ATSR) fire data, the Total Ozone Mapping Spectrometer (TOMS) aerosols data, and the MODIS cloud data, Nédélec et al. (2005) also attributed the high $\mathrm{CO}$ at these altitudes to front lifting of $\mathrm{CO}$ from large forest fires near Lake Baikal. The time and location of frontal lifting of $\mathrm{CO}$ in our FLEXPART simulations match well with the observations of high CO by Nédélec et al. (2005). Furthermore, this study provides a more explicit description on the CO transport pathways (Figs. 7 and 8). We also found this rare case demonstrate MOPITT's capability of detecting extreme high $\mathrm{CO}$ episodes through relative variations in vertical and horizontal dimensions. Corresponding to the strongest $\mathrm{CO}$ source among the three cases, MOPITT data showed the largest horizontal area with CO plumes (Fig. 4), the deepest vertical CO buildup with the highest abundances (Fig. 6), and the biggest enhancement of 200-250 ppbv from the a priori (Fig. 5).

\subsection{Case study II: 18 March 2004}

This case occurred on 18 March 2004 when high CO appeared in the MOPITT data in the lower and middle troposphere over the East China Sea (Fig. 4b). The elevated CO of 200-250 ppbv is observed between 750 and $550 \mathrm{hPa}$ vertically in MOPITT data (Fig. 5c). The departure of the MOPITT CO profile from its a priori reflects the MOPITT's vertical sensitivity (Fig. 5c). The MOPITT monthly mean, like for the other two cases, follows a typical $\mathrm{CO}$ profile pattern with $\mathrm{CO}$ concentrations being the highest near the surface and decreasing gradually with altitude. The $\mathrm{CO}$ on $18 \mathrm{March}$ 2004 was 50 ppbv higher than the monthly mean above $800 \mathrm{hPa}$. A layer of elevated CO appeared in the MOZAIC profile between 750 and $550 \mathrm{hPa}$ with a peak of $500 \mathrm{ppbv}$ around $650 \mathrm{hPa}$ (Fig. 5d). The high RH ( 90- 100\%) below $600 \mathrm{hPa}$ in the MOZAIC data suggests that the air mass experienced some uplifting process that enhanced its humidity, likely from a WCB. The MOZAIC ozone peaked ( $~ 70 \mathrm{ppbv})$ around the same altitudes as $\mathrm{CO}$, implying that ozone may be produced in the air mass carrying high $\mathrm{CO}$ during the transport process. Figure $6 \mathrm{~b}$ shows a latitude-altitude cross section averaged between the two blue dashed lines in Fig. 4b. Around $30^{\circ} \mathrm{N}$, elevated CO levels ( $\left.\sim 200 \mathrm{ppbv}\right)$ are evident around $700 \mathrm{hPa}$.

This case was simulated with GEOS-Chem to identify the sources of $\mathrm{CO}$ and to explore the transport mechanisms. The MODIS fire data suggest biomass burning over north- 


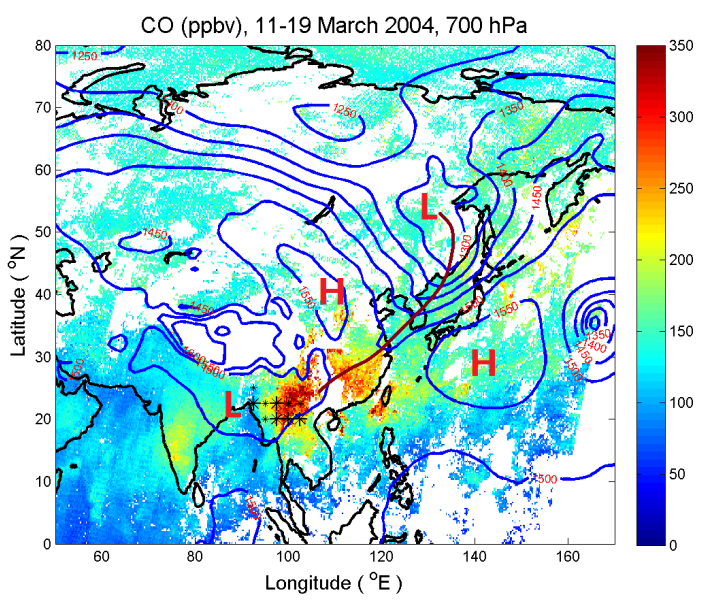

Figure 9. MOPITT CO mixing ratio at $700 \mathrm{hPa}$ from 11 to $19 \mathrm{March}$ 2004 , overlaid with the geopotential height at $850 \mathrm{hPa}$ on 17 March 2004 in blue contour and with a front shown by a brown solid line. The large and small stars denote daily mean fire counts of 100-200 and over 200 per $2.5^{\circ} \times 2.5^{\circ}$ grid area during the period, respectively. $\mathrm{L}$ and $\mathrm{H}$ indicate a low and high pressure system, respectively.

ern Indochina peninsula to be a source for the observed high $\mathrm{CO}$ (Fig. 9). The time series of fire counts over area of $20-25^{\circ} \mathrm{N}$ and $92-105^{\circ} \mathrm{E}$ peaked on 12 March 2004. Correspondingly, high CO of $\sim 300 \mathrm{ppbv}$ appeared in the MOPITT composite of 11-18 March 2004 at $700 \mathrm{hPa}$ over northern Indochina peninsula (Fig. 9). This source was also recognized in the GEOS-Chem simulation (Fig. 10b). In addition, the anthropogenic source concentrated over the North China Plain (approximately $30-40^{\circ} \mathrm{N}, 110-125^{\circ} \mathrm{E}$ ) was identified as another source (Fig. 10c). The fire-induced CO spread larger areas from south to north than the anthropogenic CO. Figure 11 shows the latitude-altitude cross sections of the GEOS-Chem simulations of $\mathrm{CO}$, fire-induced $\mathrm{CO}$, and anthropogenic $\mathrm{CO}$, respectively, along $130^{\circ} \mathrm{E}$ on 18 March 2004. CO abundances from both sources were high around $700 \mathrm{hPa}$ (Fig. $11 \mathrm{~b}$ and c) between 25 and $35^{\circ} \mathrm{N}$ across $130^{\circ} \mathrm{E}$ where MOPITT also observed high CO (Fig. 6b).

The different $\mathrm{CO}$ distributions for the two sources in three dimensions (Figs. 10 and 11) reflect rather different transport pathways and uplifting mechanisms. We found that the transport of the fire-induced $\mathrm{CO}$ can be divided into four processes. First, the $\mathrm{CO}$ was orographically lifted along the Hengduan Mountains from the surface to $\sim 750 \mathrm{hPa}$. The lifted CO is shown in Fig. 12 around $100^{\circ} \mathrm{E}$ on a longitudealtitude cross section along $22^{\circ} \mathrm{N}$. Then, the uplifted $\mathrm{CO}$ experienced two separate transports. In the second process, part of the lifted CO was further transported upward to 400$300 \mathrm{hPa}$, shown as a bulb in Fig. 12 around $105^{\circ}$ E. This is due to strong convection, possibly caused by a frontal system developed on 17 March 2004 (Fig. 9), and interplay with the lee-side troughs east of the Hengduan Mountains.
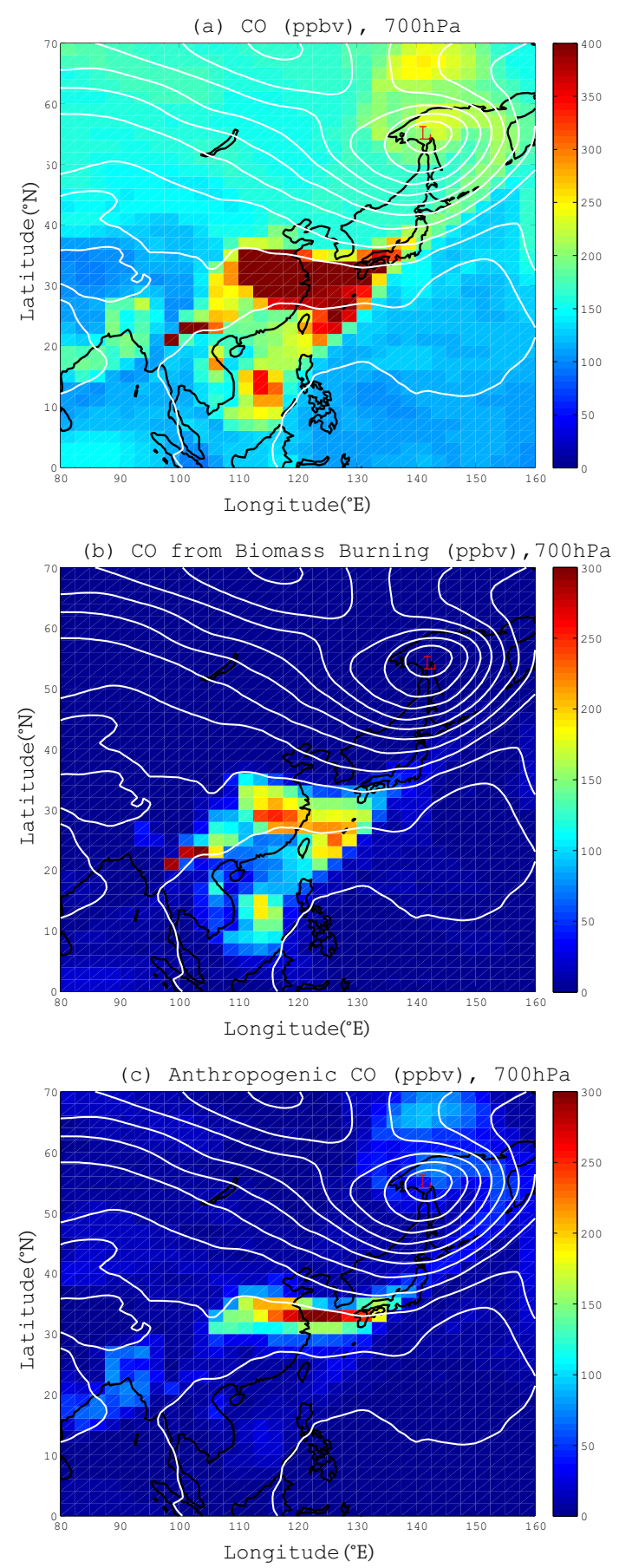

Figure 10. (a) CO, (b) $\mathrm{CO}$ from biomass burning, and (c) $\mathrm{CO}$ from the anthropogenic source on 17 March 2004 at 00:00 UTC, simulated by GEOS-Chem. The geopotential height at $700 \mathrm{hPa}$ is indicated with white contours. L indicates a low pressure system.

The vertical velocity reached $0.2 \mathrm{~m} \mathrm{~s}^{-1}$ in FNL data around this level (not shown). The ECMWF (European Centre for Medium-Range Weather Forecasts) data also show northeastward airflow from Indochina peninsula with high potential energy (warm and wet) available for strong convection. 


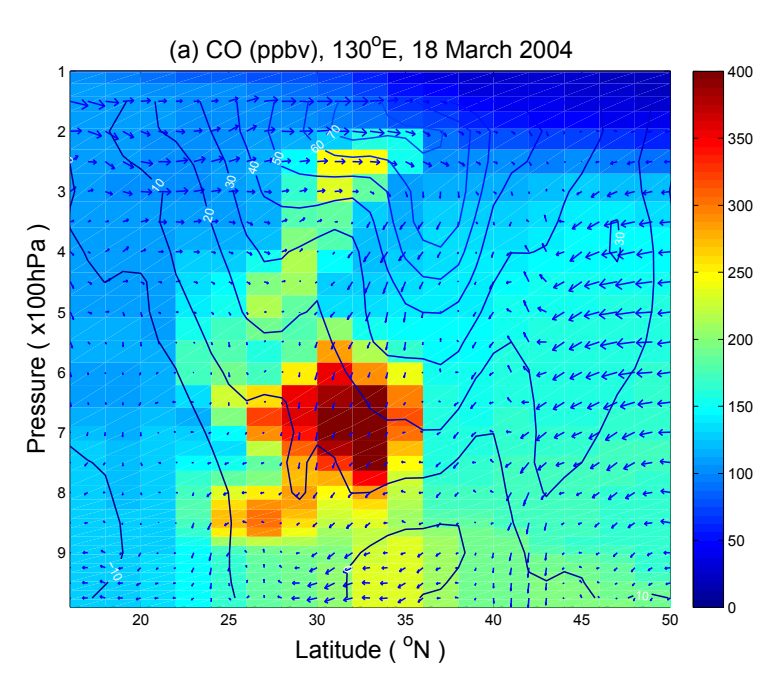

(b) CO from Biomass Burning (ppbv), $130^{\circ} \mathrm{E}, 18$ March 2004

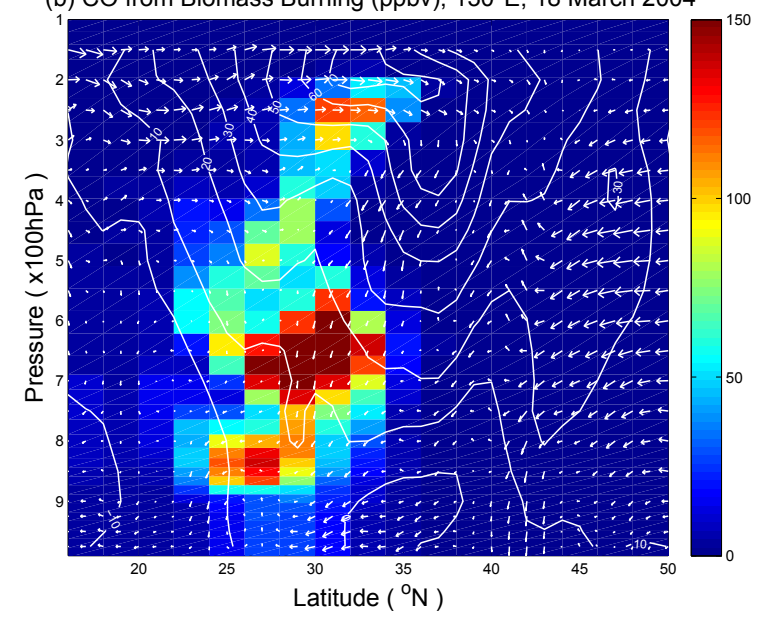

(c) Anthropogenic $\mathrm{CO}$ (ppbv), $130^{\circ} \mathrm{E}, 18$ March 2004

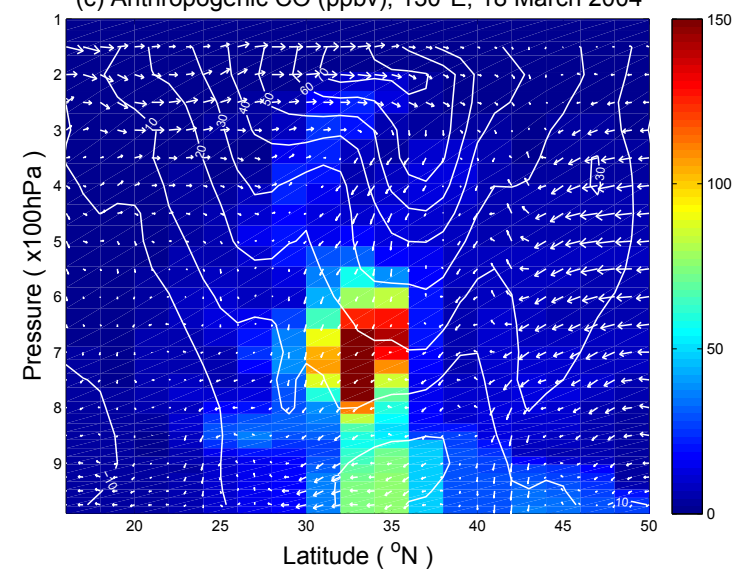

Figure 11. Latitude-altitude cross sections along $130^{\circ} \mathrm{E}$ of (a) $\mathrm{CO}$, (b) $\mathrm{CO}$ from biomass burning, and (c) anthropogenic $\mathrm{CO}$ on 18 March 2004 at 00:00 UTC, simulated by GEOS-Chem. The contour lines indicate $U$ wind speed $\left(\mathrm{m} \mathrm{s}^{-1}\right)$. Vectors are for wind directions in $V$ and $W$. For a better illustration, $W$ is enlarged by a factor of 100 .

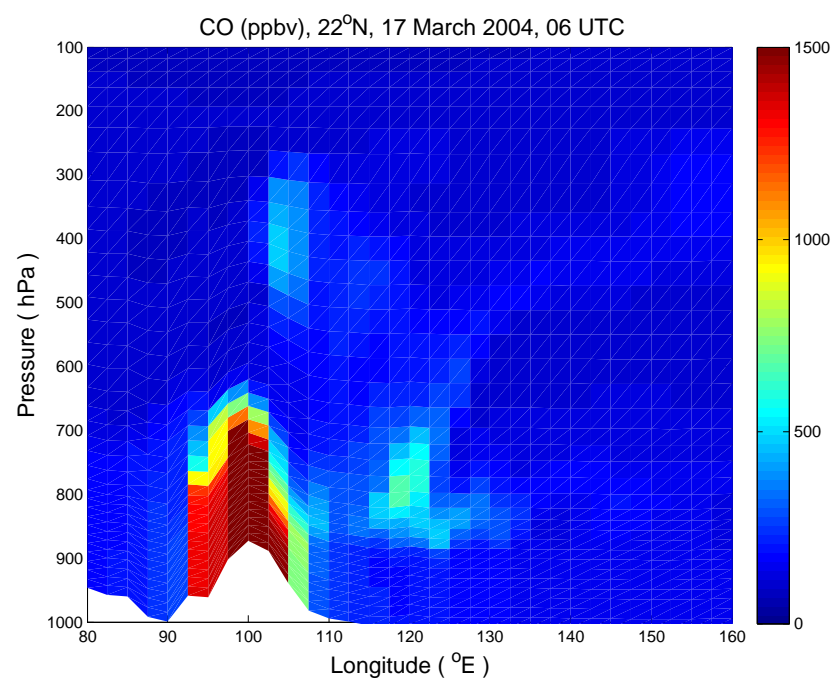

Figure 12. A longitude-altitude cross section of $\mathrm{CO}$ along $22^{\circ} \mathrm{N}$ on 17 March 2004 at 06:00 UTC, simulated by GEOS-Chem. The topography of the Hengduan Mountains is indicated in white.

All of these suggest that the strong convection over the leeside troughs rapidly lifted $\mathrm{CO}$ up to $\sim 350 \mathrm{hPa}$. In fact, the orographic lifting and topography-induced convection are quite common in this region; therefore, high $\mathrm{CO}$ often appears at these two altitudinal levels in March as simulated by GEOS-Chem (not shown). On 17 March, the lifted CO was with even higher concentrations $(\sim 500 \mathrm{ppbv})$ around $400 \mathrm{hPa}$ than the monthly mean because of its fire origin and the presence of the lee-side troughs. In the third process, the uplifted $\mathrm{CO}$ around $400-300 \mathrm{hPa}$ (near $105^{\circ} \mathrm{E}$ in Fig. 12) was transported northeastward by strong winds along the front in the upper troposphere, reaching the East China Sea (near $30^{\circ} \mathrm{N}, 130^{\circ} \mathrm{E}$ ) on $18 \mathrm{March}$. This transport enables high CO from forest fires in southern Asia in low latitudes to rapidly reach the upper troposphere in the mid-latitudes. In the fourth process, paralleling to the second and third, part of the orographically uplifted $\mathrm{CO}$ was afloat around $\sim 700 \mathrm{hPa}$ because of lee-side-trough-induced convection. This $\mathrm{CO}$ was transported eastward along the isobars of the low pressure system around $700 \mathrm{hPa}$ (Figs. 10 and 12). This process occurred at lower altitudes than processes two and three. The transport was slower and it took a longer time (from 15 to 18 March) for the CO to reach the East China Sea. Processes two and three brought $\mathrm{CO}$ to the upper troposphere (200$300 \mathrm{hPa}$ in Fig. 11b), while process four increased $\mathrm{CO}$ in the lower to middle troposphere (700-500 hPa in Fig. 11b). For the anthropogenic CO from the North China Plain, the vertical transport was mainly carried out by frontal lifting on 17 March 2004 (Fig. 9) and then the uplifted CO was transported eastward along $30^{\circ} \mathrm{N}$ (Fig. 10c). Consequently, the total $\mathrm{CO}$ shows a buildup centered near $700 \mathrm{hPa}$ around $30^{\circ} \mathrm{N}$ and $130^{\circ} \mathrm{E}$, mostly coming from the two $\mathrm{CO}$ sources (Fig. 11a-c). 
The Hengduan Mountains run mainly north to south, with elevations ranging from 1300 to $6000 \mathrm{~m}$. This topography provides a favorable condition for the formation of the leeside troughs if meteorology is satisfied. Such troughs promote vertical transport of $\mathrm{CO}$ on the east side of the mountains (in the second and fourth processes), while the orographic lifting occurred on the west side of the mountains (in the first process). The lee-side troughs occur most and least frequently in spring and summer, respectively. Interannual variation of the lee-side troughs is also observed.

Comparison of the vertical $\mathrm{CO}$ distributions between MOPITT and GEOS-Chem (Fig. 6b vs. Fig. 11a) suggests that MOPITT can generally capture vertical transport of $\mathrm{CO}$ from forest fires and anthropogenic sources, although the magnitude of CO in MOPITT data was lower and there were also substantial gaps in the MOPITT images due to convective clouds. In the MOPITT data, high CO of $\sim 200$ ppbv reached up to $200 \mathrm{hPa}$. In the lower to middle troposphere, elevated CO ( 200 ppbv) was centered around 650-700 hPa. These features are similar to the GEOS-Chem simulations. Note that the $\mathrm{CO}$ buildup around $300 \mathrm{hPa}$ in the GEOS-Chem simulation (Fig. 11a and b) was reflected in the MOPITT data (Fig. 6b), but not as obvious as in the simulation since the MOPITT retrievals are smoothed with the averaging kernels. This CO is also shown as a little bump around $300 \mathrm{hPa}$ in MOPITT vertical profile in Fig. 5c. This buildup is missing in the MOZAIC profile (Fig. 5d) because the aircraft flew towards the north and outside the region with high $\mathrm{CO}$ (Fig. 4b).

As the backward trajectories, starting from the boxed area at $700 \mathrm{hPa}$ in Fig. 4b, indicated the most particles came from the large fire in the Indochina peninsula starting from 11 March 2004, we released air particles in FLEXPART over the fire regions from the surface to $1 \mathrm{~km}$ on 11 March 2004, and forward trajectories were simulated to track down the air parcels until 18 May 2004 at 02:00 LT. Taking the same zonal means as for Fig. 6b, it is found that the vertical distribution of particle concentrations is similar to that in Fig. $6 \mathrm{~b}$ with the highest particle concentrations between 4 and $5 \mathrm{~km}$ (not show). As simulated by FLEXPART, the outflow of the high CO finally reached the west coast of the United States with particles mainly distributed around $5 \mathrm{~km}$ in altitude. High CO observed in East Asia in this case appeared the mostly southerly among the three (Fig. 6), leading to a most southerly outflow.

The strong lee-side-trough-induced convection described in the fourth process was first proposed by Lin et al. (2009) who found that the lee-side troughs above the Indochina peninsula play a significant role in uplifting ozone there. In this study, we found these lee-side troughs can promote lifting of $\mathrm{CO}$ even up to the upper troposphere (in the second process, Fig. 12). It is the interplay of the lee-side troughs and the cyclone in the northeast of China which formed a front system that transported CO from the Indochina peninsula upward.

\subsection{Case study III: 10 April 2005}

In this case, MOPITT observed high $\mathrm{CO}$ of $\sim 250 \mathrm{ppbv}$ at $300 \mathrm{hPa}$ near the east coast of Japan on 10 April 2005 (Fig. 4c). Like for the other cases, the mean MOPITT profile was taken over a boxed area (in Fig. 4c) upwind of the MOZAIC measurement for comparison. The MOPITT vertical profile clearly shows a $\mathrm{CO}$ peak around $300 \mathrm{hPa}$, where it departs from the MOPITT monthly mean (Fig. 5e). Compared with the other cases, MOPITT CO peaked at higher altitudes, illustrating some MOPITT vertical sensitivity even at these altitudes. In Fig. 5f, a sharp peak of 300 ppbv in MOZAIC CO is shown around $350 \mathrm{hPa}$. This peak can also be reproduced in the GEOS-Chem simulation with a lower CO abundance of $\sim 200 \mathrm{ppbv}$ (not shown). The profile of relative humidity follows closely that of $\mathrm{CO}$, with values up to $90-100 \%$ around $350 \mathrm{hPa}$, implying that the elevated $\mathrm{CO}$ was lifted to this level from the lower troposphere by a cyclone system along its WCB. However, the MOZAIC ozone profile varies differently from the $\mathrm{CO}$ profile. We found this was connected to a strong stratospheric intrusion introduced by the cyclone. HYSPLIT (HYbrid Single-Particle Lagrangian Integrated Trajectory) simulations suggest that a large amount of air mass plunged around 4 April from 9 to 3-4 km over northwest of China, bringing high ozone to the lower troposphere (not shown). Another piece of evidence for a stratospheric intrusion is suggested by the low humidity between 780 and $400 \mathrm{hPa}$. Such a downwelling of stratospheric air on the back side of cyclones was also reported by Miyazaki et al. (2003). Figure 6c shows an altitude-latitude cross section averaged between 120 and $150^{\circ} \mathrm{E}$ (between two dashed lines in Fig. 4c). High CO of 200-250 ppbv appeared between 300 and $200 \mathrm{hPa}$ around $35^{\circ} \mathrm{N}$. This is a rare case in which MOPITT reports such high CO (200-250 ppbv) at these high altitudes (around $300 \mathrm{hPa}$ ). Documented CO abundances observed by MOPITT at these altitudes were $\sim 130 \mathrm{ppbv}$ over the Indian summer monsoon seasons (Kar et al., 2004), 110-150 ppbv in North America from the forest fires, chemical, and anthropogenic sources (Liu et al., 2005, 2006), and $\sim 150$ ppbv in spring at Hong Kong (Zhou et al., 2013).

The MODIS fire data show that there were indeed large fires over Indochina peninsula in 3-10 April 2005, shown as stars in Fig. 13. Using GEOS-Chem, CO from fire and anthropogenic sources was simulated to identify their respective contributions and transport pathways.

The entire process of vertical and horizontal transport of CO was well reproduced by GEOS-Chem (Fig. 14). Figure 14 a provides the $\mathrm{CO}$ distribution in the lower troposphere on 8 April 2005, while Fig. 14b and c show the CO distribution on the next day and the day after in the middle and upper troposphere, respectively. The geopotential heights at 750,450 , and $250 \mathrm{hPa}$ are overlaid with the $\mathrm{CO}$ images for each layer accordingly. On 8 April 2005, there was a cyclone developing in the east of Lake Baikal located around 110- 


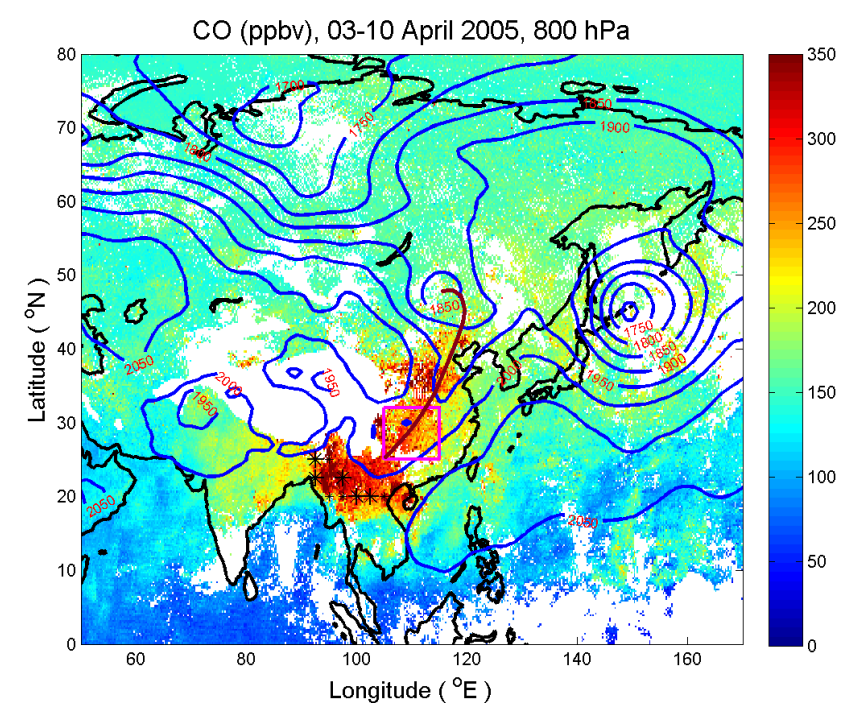

Figure 13. MOPITT CO mixing ratio at $800 \mathrm{hPa}$ from 3 to 10 April 2005 , overlaid with the geopotential height at $850 \mathrm{hPa}$ on 9 April 2005 at 00:00 UTC in blue contour and with a front as a brown solid line. The large and small stars denote daily mean fire counts of $100-200$ and over 200 per $2.5^{\circ} \times 2.5^{\circ}$ grid area during the period, respectively. The boxed area was identified as a major CO source region from the FLEXPART simulation (see text for detail).

$120^{\circ} \mathrm{E}, 45-55^{\circ} \mathrm{N}$. The surface $\mathrm{CO}$ was transported upward and northeastward along the WCB (Fig. 14a). On 9 April the cyclone moved to the east (Figs. 13 and 14b). The high CO shows a comma shape along WCB at the mid-troposphere; this shape is typical for a mature cyclone system with a WCB (Cooper et al., 2002). On 10 April, the cyclone further moved eastward and reached the Sea of Japan (Fig. 14c). The GEOS-Chem simulation shows accumulation of high $\mathrm{CO}$ over the ridge of high pressure and along the front at the upper troposphere. The GEOS-Chem simulations suggest that the outflow of the high CO reached Canada on 16 April.

The combined effects of cyclone activities, topography, and $\mathrm{CO}$ from different sources and locations are reflected in distinct $\mathrm{CO}$ signatures along the WCB. Figure 15 shows the $\mathrm{CO}$ from the fires (Fig. 15a and c) and from the anthropogenic source (Fig. 15b and d) in the middle and upper troposphere, respectively, overlaid with the geopotential height at 450 (Fig. 15a and b) and $250 \mathrm{hPa}$ (Fig. 15c and d), respectively. In the middle troposphere $(500-400 \mathrm{hPa})$, a large amount of $\mathrm{CO}$ from the fires in the Indochina peninsula was uplifted to this level through orographic lifting and strong convection on the west and east side of the Hengduan Mountains, respectively. This $\mathrm{CO}$ distributed along the middle part of the WCB on 9 April 2005 and was transported eastward on 10 April 2005 (Fig. 15a). One source of the anthropogenic $\mathrm{CO}$ was concentrated around the North China Plain (Ding et al., 2009) where high CO was evident in MOPITT data (Fig. $13,35-40^{\circ} \mathrm{N}, 100-120^{\circ} \mathrm{E}$ ). On 8 April, this $\mathrm{CO}$ was uplifted along the WCB and further transported to
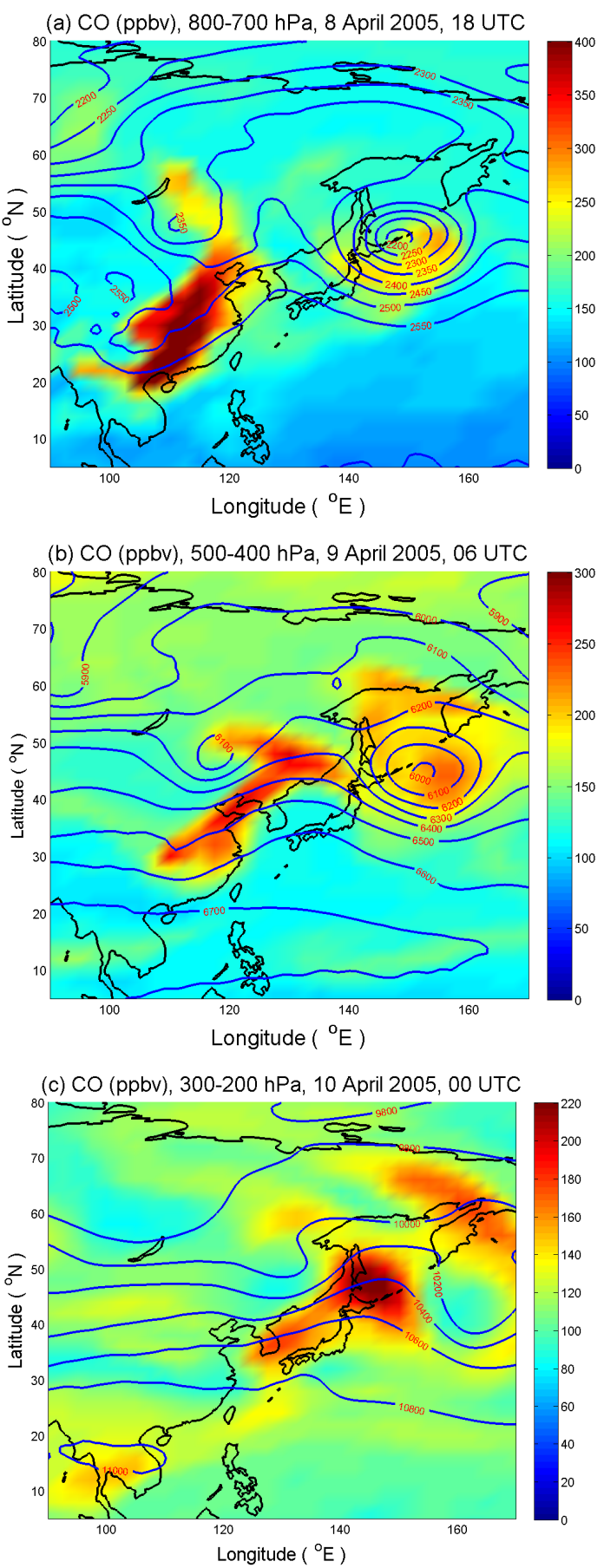

Figure 14. The GEOS-Chem simulated CO (a) on 8 April 2005 in the lower troposphere $(800-700 \mathrm{hPa})$, (b) on 9 April in the middle troposphere $(500-400 \mathrm{hPa})$, and (c) on 10 April in the upper troposphere $(300-200 \mathrm{hPa})$. The contours are the geopotential height at 850,450 , and $250 \mathrm{hPa}$, respectively.

the middle troposphere, coming across sudden elevated terrains on the way and forming the head of the comma in the cyclone system (Figs. 14b and 15b). The topography's role was noticed by Liu et al. (2003), who found a ring of conver- 


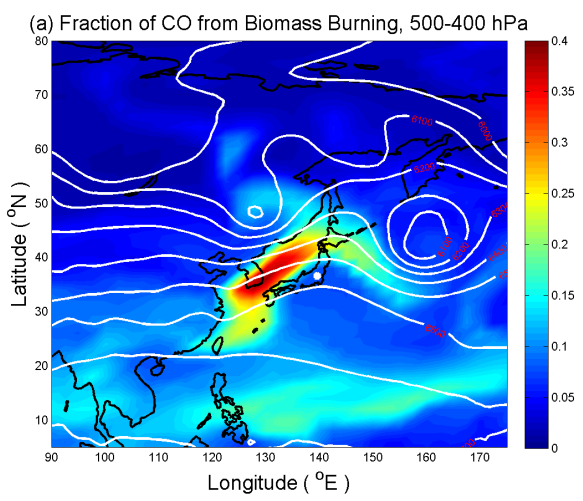

(b) Fraction of Anthropogenic CO, $500-400 \mathrm{hPa}$
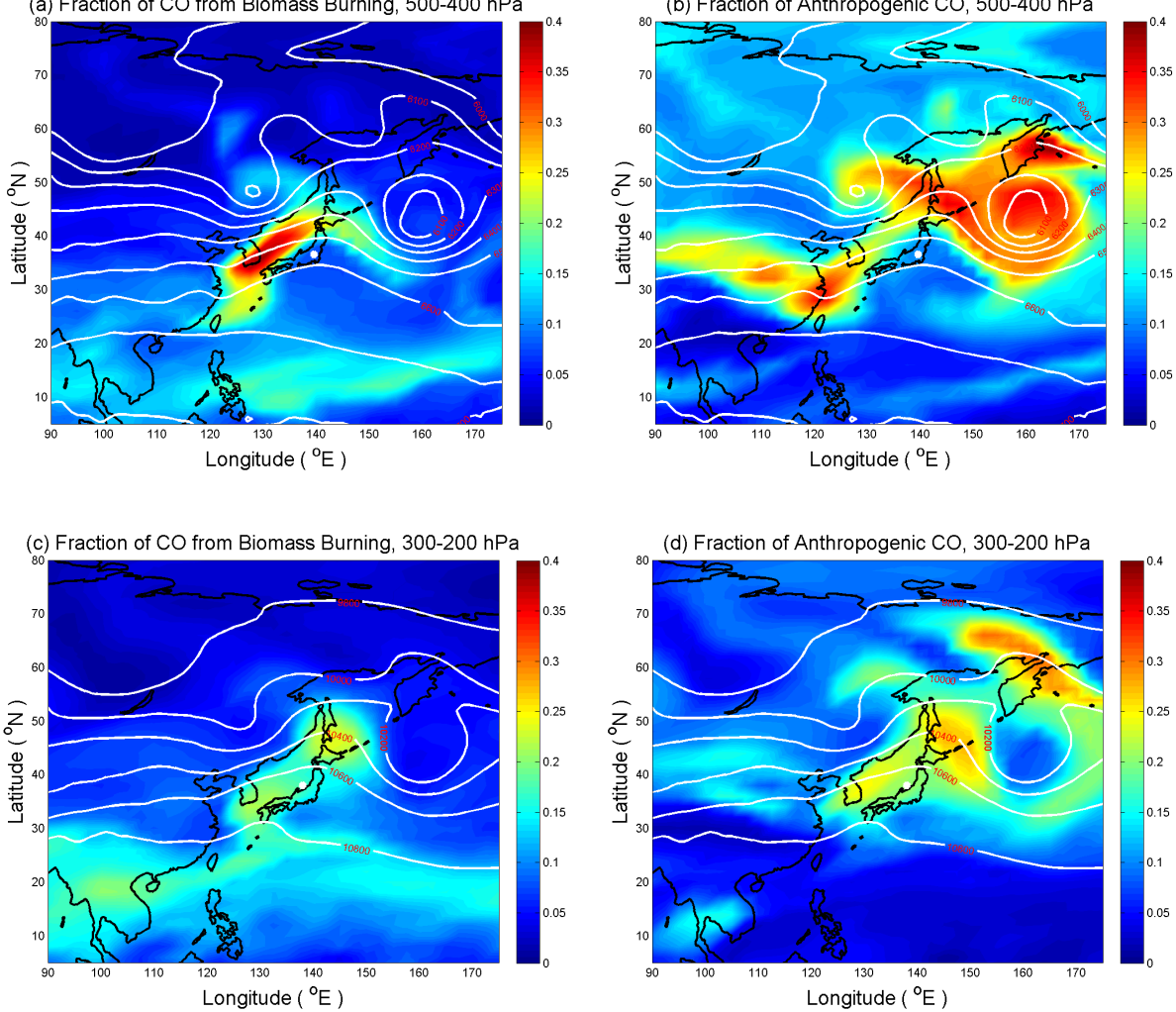

Figure 15. The GEOS-Chem simulated fractional CO (a) from biomass burning and (b) from the anthropogenic source on 10 April 2005 at 00:00 UTC in the middle troposphere (500-400 hPa). (c) and (d) are the same as for (a) and (b), respectively, but in the upper troposphere (300-200 hPa). The geopotential height at 450 and $250 \mathrm{hPa}$ is overlaid with the CO images in the middle and upper troposphere, respectively. White dots indicate the location of MOZAIC measurements.

gence around the North China Plain associated with elevated terrain, and by Ding et al. (2009), who speculated possible topography lifting in the North China Plain. In the southern end of the WCB (near $30^{\circ} \mathrm{N}, 120^{\circ} \mathrm{E}$ in Fig. 15b), the $\mathrm{CO}$ came from the anthropogenic source in the vicinity of the Sichuan Basin $\left(\sim 26-34^{\circ} \mathrm{N}, 102-110^{\circ} \mathrm{E}\right)$. This $\mathrm{CO}$ was transported vertically to $500 \mathrm{hPa}$ on 8 April at 18:00 UTC to 9 April at 00:00 UTC. Air pollution often accumulates in the Sichuan Basin because of its special topography. The development of small-scale cyclones there is well known as the southwest vortex or Sichuan low (Tao and Ding, 1981). Accumulated pollutants there usually are transported to the free troposphere by such convection. The strong convection can last more than $6 \mathrm{~h}$ and peak at midnight (Yu et al., 2007). As this anthropogenic source is quite stable, its contribution should not be understated.

Interestingly, Lin et al. (2009) reported an observed ozone enhancement from ozonesonde data at $4 \mathrm{~km}$ in Taiwan on 11 April 2005. They proposed a new transport mechanism from their study as discussed in Sect. 4.2, in which they attributed the elevated ozone to the biomass burning in Indochina. Similarly, CO from biomass burning was also apparent over Taiwan at the middle troposphere in the GEOS-Chem simula- tion (Fig. 15a), although the maximum $\mathrm{CO}$ enhancement was north of Taiwan at this altitude.

The white dot in Fig. 15 indicates the location where MOZAIC passed over. It is clear that MOZAIC measurement at $200-300 \mathrm{hPa}$ was within the $\mathrm{WCB}$, while it was at a distance from the WCB at $500-400 \mathrm{hPa}$. This is consistent with the MOZAIC CO, ozone, RH profiles shown in Fig. 5f, suggesting that MOZAIC in fact measured air from the stratosphere at these altitudes. As the wind in the upper troposphere was stronger than in the lower troposphere, the WCB-transported CO reached further east in the upper levels (Fig. 15). The simulations suggest that over the boxed area in the MOPITT image in Fig. $4 \mathrm{c}$ at $300 \mathrm{hPa}$, the fire and anthropogenic sources contributed approximately 15 and $20 \% \mathrm{CO}$, respectively. It is noteworthy that there were large gaps in MOPITT data north of $33^{\circ} \mathrm{N}$ (Fig. $4 \mathrm{c}$ ) where $\mathrm{CO}$ abundances may be even higher than the MOPITT CO south of $33^{\circ} \mathrm{N}$ as suggested by the GEOS-Chem simulation (Fig. 14c). These gaps were caused by clouds associated with the cyclone system. The complication due to clouds is a problem with an optical instrument like MOPITT. This is why this case is rare in which high $\mathrm{CO}$ was observed by both MOPITT and MOZAIC under a frontal system. 
In this case, the strong part of the front (close to the centre of the cyclones) swept southern China, where $\mathrm{CO}$ was high (Fig. 13). Along the front $\left(30-40^{\circ} \mathrm{N}, 100-120^{\circ} \mathrm{E}\right)$, the temperature gradient at $925 \mathrm{hPa}$ was as high as $4.9^{\circ} \mathrm{C}$ per degree. Strong ascents occurred ahead of the front, with vertical velocity being $\sim 0.05 \mathrm{~m} \mathrm{~s}^{-1}$ at 900 and $\sim 0.20 \mathrm{~m} \mathrm{~s}^{-1}$ at $750 \mathrm{hPa}$, increasing with altitude until $300-250 \mathrm{hPa}$ where the maximum vertical velocity was $0.26 \mathrm{~m} \mathrm{~s}^{-1}$. Consequently, the high $\mathrm{CO}$ can be rapidly lifted to the upper troposphere in this case.

FLEXPART was also used to trace down high $\mathrm{CO}$ in the MOPITT image by releasing air particles in the boxed area in Fig. 6c (indicated by a bar in Fig. 4c). We found that the most $\mathrm{CO}$ came from the southwest part of China (boxed area in Fig. 13) where MOPITT CO composite of 3-10 April 2005 shows high $\mathrm{CO}$ of $250-300 \mathrm{ppbv}$ at $800 \mathrm{hPa}$. This $\mathrm{CO}$ was lifted along the WCB described above. This agrees with the GEOS-Chem simulation which attributed the major CO source in the upper troposphere to the anthropogenic CO, likely from the Sichuan Basin (Fig. 15d).

\section{Discussion}

New insights gained from this study and suggestions for future work are discussed as follows.

\subsection{Observations of high CO episodes}

In the three $\mathrm{CO}$ episodes, high $\mathrm{CO}$ abundances $300-550 \mathrm{ppbv}$ were observed by MOZAIC in the free troposphere (Fig. 5). The $\mathrm{CO}$ abundances are among the highest documented at these altitudes in East Asia. Ding et al. (2009) observed high CO episode of $\sim 1185 \mathrm{ppbv}$ at $2.6 \mathrm{~km}(850-700 \mathrm{hPa})$ over the North China Plain in summer 2007. Nédélec et al. (2005) found $\mathrm{CO}$ up to $800 \mathrm{ppbv}$ above $8 \mathrm{~km}(\sim 400 \mathrm{hPa})$ near the fire region of Lake Baikal on 3 and 4 June 2003. Highest CO concentrations during TRACE-P were between 250 and $300 \mathrm{ppbv}$ from 2 to $12 \mathrm{~km}$ (Heald et al., 2003; Liu et al., 2003; Miyazaki et al., 2003). Occurrences of such high $\mathrm{CO}$ episodes are not by chance. They reflect the uniqueness and complexity of meteorology, orography, vegetation covers, and CO sources in East Asia. For example, in all the cases, biomass burning occurred from regions with dense vegetation covers and with most active forest fires in East Asia (Schultz, 2002; Duncan et al., 2003). These fires are usually most active in summer in boreal forest in Russia (like in case 2003) and in spring in the southern East Asia (like cases 2004 and 2005) thus enhancing chances of high CO episodes in these seasons.

The frequency of occurrences of such high $\mathrm{CO}$ is illustrated in Table 2. As the three cases occurred near Japan, MOZAIC data around the vicinity of Narita from 2001 to 2006 are summarized, showing occurrences of various CO abundance ranges in the boundary layer (the surface-850), the lower (850-600), middle (600-400), and upper (400$200 \mathrm{hPa}$ ) troposphere. Among all the data in the upper troposphere, CO abundances occurred 93 times $(17 \%)$ between 200 and 300, 19 times (4\%) between 300 and 400, and 6 times $(1 \%)$ over $400 \mathrm{ppbv}$. In the middle troposphere, the fraction of occurrences of CO within 200-300,300-400, and over 400 ppbv was 14,3 , and $2 \%$, respectively. In the boundary layer, the highest occurrences of $\mathrm{CO}$ abundances $(38 \%$ of all the data in the layer) were within a range of 200$300 \mathrm{ppbv}$, while the range was within 100-200 ppbv in the lower $(47 \%)$, middle $(74 \%)$, and upper troposphere $(66 \%)$. Seasonally, there were more high CO episodes in the higher altitudes in spring and summer than in fall and winter.

The frequency of such high $\mathrm{CO}$ episodes is also examined in the GEOS-Chem simulations and MOPITT observations in the vicinity of Narita $\left(126-140^{\circ} \mathrm{E}, 30-40^{\circ} \mathrm{N}\right)$ in 2005 (Table 3 ). A count is added to a $\mathrm{CO}$ range if the daily maximum $\mathrm{CO}$ in the area $\left(126-140^{\circ} \mathrm{E}, 30-40^{\circ} \mathrm{N}\right)$ falls into that $\mathrm{CO}$ range. Thus, the total counts for all the $\mathrm{CO}$ ranges at a given layer are 365 in 2005 for GEOS-Chem, while the counts are 281 for MOPITT due to missing data. To minimize noise in daily MOPITT data, only when there are at least 10 data in the area with the maximum $\mathrm{CO}$ falling into a given $\mathrm{CO}$ range, a count is added. GEOS-Chem can simulate CO up to $400 \mathrm{ppbv}$ in the upper troposphere, while the maximum $\mathrm{CO}$ in MOPITT is lower so that different $\mathrm{CO}$ ranges are used in Table 3. Overall, MOZAIC, MOPITT, and GEOS-Chem all show a high frequency of high CO (larger than 200 ppbv) at the surface, progressively shifting to a high frequency of low CO (less than $200 \mathrm{ppbv}$ ) at the upper troposphere. Between 400 and $200 \mathrm{hPa}$, CO with 200-300 ppbv occurred 1.2 times every 10 days in GEOS-Chem, which was slightly lower than in MOPITT (1.8 times) and MOZAIC (1.7 times). Overall, MOZAIC observed 2-5\% more vertical transport of high $\mathrm{CO}(>300 \mathrm{ppbv})$ to the upper troposphere than GEOSChem, while the latter simulated 10-20\% more frequently the transport to the middle and lower troposphere with similar or lower $\mathrm{CO}$ abundances.

It is likely that on average, the extremely high $\mathrm{CO}$ episodes ( $\sim 500$ ppbv), such as the 2003 and 2004 cases (Fig. 5), occurred 2-5 times per 100 days in their respective altitudes over the East China Sea and the Sea of Japan (Tables 2 and 3). With a lower CO abundances of 200-300 ppbv (case 2005), the frequency for the air mass to be transported to $400-200 \mathrm{hPa}$ is $1-2$ times per 10 days (Tables 2 and 3 ). The frequency can be even higher in spring and summer, approximately once a week (Table 2). Significant impacts of such vertical transport can be expected on the air quality downwind and on the global climate. The transport mechanisms and $\mathrm{CO}$ source contributions revealed in this study can also be applicable for $\mathrm{CO}$ episodes with lower $\mathrm{CO}$ abundances or at lower altitudes. 
Table 2. Occurrences of various CO ranges at different altitudes in the MOZAIC measurements in the vicinity of Narita from 2001 to 2006.

\begin{tabular}{|c|c|c|c|c|c|c|c|c|c|c|c|c|c|}
\hline \multirow{3}{*}{ Season } & \multirow{3}{*}{$\begin{array}{r}\text { Pressure } \\
(\mathrm{hPa})\end{array}$} & \multicolumn{6}{|c|}{ Occurrence } & \multicolumn{6}{|c|}{ Fractional occurrence (\%) } \\
\hline & & \multirow[b]{2}{*}{$0-100$} & \multicolumn{4}{|c|}{ CO range (ppbv) } & \multirow[b]{2}{*}{ All } & \multicolumn{5}{|c|}{ CO range (ppbv) } & \multirow[b]{2}{*}{ All } \\
\hline & & & $100-200$ & $200-300$ & $300-400$ & $>400$ & & $0-100$ & $100-200$ & $200-300$ & $300-400$ & $>400$ & \\
\hline \multirow[t]{4}{*}{ All } & $400-200$ & 67 & 354 & 93 & 19 & 6 & 539 & 12 & 66 & 17 & 4 & 1 & 100 \\
\hline & $600-400$ & 36 & 359 & 69 & 15 & 8 & 487 & 7 & 74 & 14 & 3 & 2 & 100 \\
\hline & $850-600$ & 17 & 180 & 150 & 31 & 6 & 384 & 4 & 47 & 39 & 8 & 2 & 100 \\
\hline & Surface- -850 & 4 & 60 & 142 & 83 & 88 & 377 & 1 & 16 & 38 & 22 & 23 & 100 \\
\hline \multirow[t]{4}{*}{ Spring } & $400-200$ & 11 & 96 & 28 & 12 & 2 & 149 & 7 & 64 & 19 & 8 & 1 & 100 \\
\hline & $600-400$ & 1 & 101 & 29 & 9 & 3 & 143 & 1 & 71 & 20 & 6 & 2 & 100 \\
\hline & $850-600$ & 0 & 38 & 55 & 20 & 5 & 118 & 0 & 32 & 47 & 17 & 4 & 100 \\
\hline & Surface- 850 & 0 & 14 & 44 & 27 & 29 & 114 & 0 & 12 & 39 & 24 & 25 & 100 \\
\hline \multirow[t]{4}{*}{ Summer } & $400-200$ & 14 & 132 & 41 & 4 & 4 & 195 & 7 & 68 & 21 & 2 & 2 & 100 \\
\hline & $600-400$ & 13 & 138 & 22 & 1 & 2 & 176 & 7 & 78 & 13 & 1 & 1 & 100 \\
\hline & $850-600$ & 14 & 80 & 50 & 6 & 0 & 150 & 9 & 53 & 33 & 4 & 0 & 100 \\
\hline & Surface -850 & 4 & 32 & 48 & 30 & 36 & 150 & 3 & 21 & 32 & 20 & 24 & 100 \\
\hline \multirow[t]{4}{*}{ Fall } & $400-200$ & 30 & 61 & 15 & 2 & 0 & 108 & 28 & 56 & 14 & 2 & 0 & 100 \\
\hline & $600-400$ & 20 & 50 & 11 & 2 & 1 & 84 & 24 & 60 & 13 & 2 & 1 & 100 \\
\hline & $850-600$ & 3 & 30 & 17 & 3 & 0 & 53 & 6 & 57 & 32 & 6 & 0 & 100 \\
\hline & Surface- 850 & 0 & 10 & 20 & 12 & 11 & 53 & 0 & 19 & 38 & 23 & 21 & 100 \\
\hline \multirow[t]{4}{*}{ Winter } & $400-200$ & 12 & 65 & 9 & 1 & 0 & 87 & 14 & 75 & 10 & 1 & 0 & 100 \\
\hline & $600-400$ & 2 & 70 & 7 & 3 & 2 & 84 & 2 & 83 & 8 & 4 & 2 & 100 \\
\hline & $850-600$ & 0 & 32 & 28 & 2 & 1 & 63 & 0 & 51 & 44 & 3 & 2 & 100 \\
\hline & Surface- 850 & 0 & 4 & 30 & 14 & 12 & 60 & 0 & 7 & 50 & 23 & 20 & 100 \\
\hline
\end{tabular}

\subsection{The role of topography}

East Asia's topography varies significantly across its vast width, increasing from east to west, with a variety of terrains. This study found that topography there affected the three cases in different ways. In addition to its general function in orographic lifting (in cases 2004 and 2005), topography also interplay with frontal systems and enhance the uplifting substantially in the North China Plain (in cases 2004 and 2005). It is notable that $\mathrm{CO}$ transports from south to north along elevated terrain over China (in case 2005, Fig. 14a). Under the influence of the Tibetan Plateau, the southwest vortex (or the Sichuan low) is formed (Tao and Ding, 1981) and can facilitate strong convection in the Sichuan Basin (in case 2005).

In particular, topography-induced convection due to the lee-side troughs east of the Hengduan Mountains, proposed by Lin et al. (2009), offers a new mechanism for vertical transport of pollution from the region (in cases 2004 and 2005). Lin et al. (2009) mainly aimed at pollution transport to the lower and middle troposphere. Extending from Lin et al. (2009), this study found such a mechanism to be plausible in explaining pollution transport to the upper troposphere. We found that the impacts of the topography-induced convection on vertical $\mathrm{CO}$ transport vary substantially from year to year. A study on such interannual variation is underway.

\subsection{The implications of WCB trends on uplifting of CO}

Extratropical cyclones and associated frontal activities are important in lifting $\mathrm{CO}$ from the boundary layer to the free troposphere. This also applies to other air pollutants. Zhao et al. (2008) found that the influence of Asian dust storms on North American ambient particulate matter levels is highly related to the height to which the frontal cyclones in East Asia can lift dust. Although many functions and characteristics of WCBs have been recognized by earlier studies, we found some details new or unique for the three cases. In case 2004, it is the interplay of the lee-side troughs and the cyclone in the northeast of China that transported $\mathrm{CO}$ from the Indochina peninsula upward. The high $\mathrm{CO}$ in this case appeared the most southerly among the three, leading to a most southerly outflow. In case 2005 , the downwelling of stratospheric air on the back side of cyclones was recognized. The $\mathrm{CO}$ along various parts of the WCB was identified to be of fire origin from Indochina and anthropogenic origin from Sichuan and the North China Plain. The source allocation was sensitive to the location of the front. Comparing cases 2004 and 2005, we found that uplifting of CO to the upper troposphere became more possible when large $\mathrm{CO}$ sources coincided with the strongest part of a WCB.

In East Asia, cyclones occur most frequently in two regions in spring and summer: one over the lee sides of the Altai-Sayan and the other in the East China Sea and the Sea of Japan (Chen et al., 1991; Yue and Wang, 2008). These are the locations and seasons where and when we can expect 
Table 3. Occurrences of various CO ranges in GEOS-Chem simulations and MOPITT observations in the vicinity of Narita $\left(126-140^{\circ} \mathrm{E}\right.$ $\left.30-40^{\circ} \mathrm{N}\right)$ in 2005 .

\begin{tabular}{|c|c|c|c|c|c|c|c|c|c|c|c|c|}
\hline \multirow{3}{*}{$\begin{array}{l}\text { Pressure } \\
(\mathrm{hPa})\end{array}$} & \multicolumn{6}{|c|}{ GEOS-Chem: fractional occurrence ( \%) } & \multirow{3}{*}{$\begin{array}{l}\text { Pressure } \\
(\mathrm{hPa})\end{array}$} & \multicolumn{5}{|c|}{ MOPITT: fractional occurrence (\%) } \\
\hline & \multicolumn{6}{|c|}{ CO range (ppbv) } & & \multicolumn{5}{|c|}{ CO range (ppbv) } \\
\hline & $0-100$ & 100-200 & $200-300$ & $300-400$ & $>400$ & All & & $0-100$ & 100-200 & $200-250$ & $>250$ & All \\
\hline 200-100 & 12 & 87 & 1 & 0 & 0 & 100 & 200-100 & 38 & 45 & 11 & 6 & 100 \\
\hline 400-200 & 0 & 87 & 12 & 1 & 0 & 100 & $400-200$ & 4 & 68 & 18 & 10 & 100 \\
\hline $600-400$ & 0 & 53 & 35 & 11 & 1 & 100 & 600-400 & 6 & 86 & 6 & 1 & 100 \\
\hline $850-600$ & 0 & 20 & 46 & 25 & 8 & 100 & $800-600$ & 7 & 67 & 20 & 6 & 100 \\
\hline $1000-850$ & 0 & 7 & 46 & 35 & 11 & 100 & $1000-800$ & 2 & 16 & 18 & 64 & 100 \\
\hline
\end{tabular}

similar events to happen in the future. Chen et al. (1991) suggested a decline in cyclonic events in East Asia from 1957 to 1977 and no such decline from 1977 to 1987 . Recently, an analysis for a longer term from 1951 to 2010 based on ensembles of twentieth century reanalysis (20CR) showed a decreasing trend in the northern part of the Sea of Japan and an increasing trend over the southern part of the Sea of Japan and the lee side of the Altai-Sayan in summer (Wang et al., 2013). The implications of these trends on uplifting of CO deserve further investigation. It would be helpful to conduct statistical analysis of the CO source distribution along WCBs in East Asia in the future.

\subsection{Model simulations of pollution transport}

Pollution transport can be tracked computationally with Eulerian and Lagrangian approaches, as represented by GEOSChem and FLEXPART models, respectively. GEOS-Chem can not only track transport of $\mathrm{CO}$ (a physical process) but also consider chemical reactions during the transport while FLEXPART can visualize transport pathways and pin down source regions effectively, without considering chemical functions in the meantime. GEOS-Chem can also fill the gaps in MOPITT satellite data (Figs. 10, 11, and 14). We found that GEOS-Chem simulates the observed aircraft and satellite CO well in cases 2004 and 2005 but cannot fully reproduce the elevated CO in MOZAIC data in case 2003. The simulated $\mathrm{CO}$ plume is with lower mixing ratios and at lower altitudes than in the MOZAIC data. This is possibly due to an underestimated fire inventory or conservative parameterizations in simulating large forest fires or both in GEOS-Chem. Nassar et al. (2009) reported underestimated CO over the 2006 Indonesia fire region by GEOS-Chem, in comparison with the Tropospheric Emission Spectrometer (TES) observations. FLEXPART can generally simulate the three cases, strikingly well sometimes in agreement with observed details in space and time, although discrepancies between FLEXPART and satellite and aircraft observations can be found in various places on small scales. FLEXPART simulates strong sources well but sometimes omits weak sources.

\subsection{Applications of MOPITT data}

We analyzed MOPITT data from two aspects: vertical sensitivity on the synoptic scale. Both are challenging and have not been studied adequately. Large gaps due to clouds and the limited MOPITT swath make application of MOPITT on the synoptic-scale difficult. Thus, application of MOPITT data over East Asia were mostly focused on monthly or seasonal scales (Tanimoto et al., 2008; Zhao et al., 2010; Hao et al., 2011; Liu et al., 2011; Zhou et al., 2013; Su et al., 2012). This study shows that even with large gaps, daily MOPITT data can capture vertical disturbances of $\mathrm{CO}$ on the synoptic scale, which are usually diluted on longer timescales. This study also suggests the importance of filling the gaps with other satellite data or in designing new satellite instruments, for the purpose of detecting such variation over large areas on regional and global scales.

Typically for satellite remote-sensing products, the MOPITT retrieval at a specific pressure level is influenced by $\mathrm{CO}$ from other levels and thus its retrieval at that pressure level can be biased. However, MOPITT can more accurately measure the average $\mathrm{CO}$ mixing ratio over a thick layer, resulting in a coarse vertical resolution. It was suggested that the vertical variation in $\mathrm{CO}$ cannot be fully resolved in earlier applications of MOPITT data (Jacob et al., 2003). This study addressed the MOPITT vertical sensitivity with new MOPITT V5 data and found enhanced vertical sensitivity in V5 data in the free troposphere, even in the upper troposphere, in addition to in the boundary layer emphasized by Worden et al. (2010) and Deeter et al. (2012). The enhanced DFSs and the averaging kernels in V5 illustrated by Worden et al. (2010) and Deeter et al. (2012) are supported (Figs. 1 and 5 and Sect. 3).

In Fig. 5, the smoothed MOZAIC profiles were calculated using the averaging kernels and the a priori in an area upwind of the MOZAIC measurement within $0-10^{\circ}$ distance for each case as there were no MOPITT data available at the exact locations of the MOZAIC measurements. Although this may introduce some bias, the averaging kernel smoothed MOZAIC profiles in V5 show more vertical structure in $\mathrm{CO}$ than an earlier version of MOPITT data in Jacob et al. (2003, 
in their Fig. 4). Overall, this study found (1) MOPITT can differentiate the magnitude of $\mathrm{CO}$ plumes originated from strong or weak sources (Figs. 4, 5, and 6); (2) MOPITT can distinguish elevated $\mathrm{CO}$ in the lower, middle, and upper troposphere (Figs. 4, 5, and 6); (3) the shape of CO plumes in vertical direction matches with simulations of GEOS-Chem and FLEXPART, sometimes remarkably well (Figs. 6, 8, and 11); and (4) there is more vertical structure in CO in new V5 than in earlier versions of MOPITT data (Fig. 5).

It is the relative variations in MOPITT CO data that help diagnose $\mathrm{CO}$ transport vertically or horizontally. This study suggests using MOPITT data quantitatively with caution, especially at altitudes with high $\mathrm{CO}$ plumes because, as illustrated in Figs. 5 and 6, the magnitude of elevated $\mathrm{CO}$ in the MOPITT data could be lower than that in the MOZAIC data at the altitudes where $\mathrm{CO}$ peaked. Therefore, the vertical variation of $\mathrm{CO}$, even enhanced in $\mathrm{V} 5$, is still much smoothed in MOPITT data. MOPITT can distinguish elevated $\mathrm{CO}$ in different layers of the free troposphere, yet sometimes cannot specify the exact altitude of elevated $\mathrm{CO}$ shown in the MOZAIC measurements (Figs. 5 and 6). One limitation for MOPITT's application of vertical transport is the complication of clouds, which often accompany frontal systems. As shown in cases 2004 and 2005, CO is usually high in cloudy areas. Therefore, the magnitude of $\mathrm{CO}$ abundances can be underestimated by MOPITT in these areas.

\section{Conclusions}

East Asia is characterized by its unique and complex meteorology, topography, vegetation covers, and $\mathrm{CO}$ sources. The characteristics are reflected in uplifting of $\mathrm{CO}$ illustrated in three high CO episodes during 2003-2005 in this study. Through integrated analyses of observations from the airborne MOZAIC and spaceborne MOPITT instruments and simulations from a trajectory dispersion model FLEXPART (Stohl et al., 2005) and a chemical transport model GEOSChem (Bey et al., 2001), this study draws the following conclusions.

1. In the three $\mathrm{CO}$ episodes, high $\mathrm{CO}$ abundances of 300 $550 \mathrm{ppbv}$ were observed by MOZAIC in the free troposphere over the East China Sea and the Sea of Japan. These are among the highest $\mathrm{CO}$ abundances ever documented at these altitudes. The three cases occurred when and where meteorology was favorable and $\mathrm{CO}$ sources were strong. It is likely that on average, the extremely high $\mathrm{CO}$ episodes $(\sim 500 \mathrm{ppbv})$ like cases 2003 and 2004 occurred 2-5 times every 100 days in their respective altitudes over the region, while in case 2005, episodes with a lower CO abundances (200$300 \mathrm{ppbv}$ ) occurred 1-2 times per 10 days between 400 and $200 \mathrm{hPa}$. CO episodes in even lower altitudes and with even lower abundance occurred more frequently in the region.
2. GEOS-Chem and FLEXPART simulations reveal different $\mathrm{CO}$ signatures from biomass burning and anthropogenic sources in the $\mathrm{CO}$ enhancement in the three cases, reflecting different transport pathways and mechanisms and locations of both sources. In case 2003, $\mathrm{CO}$ from large forest fires near Lake Baikal dominated the elevated CO. In case 2004, anthropogenic CO came from the North China Plain and mostly reached $\sim 700 \mathrm{hPa}$ near the East China Sea, while CO from biomass burning in Indochina was transported through two separate pathways, leading to two distinct $\mathrm{CO}$ enhancements around 700 and $300 \mathrm{hPa}$. In case 2005, along a WCB over the East China Sea and the Sea of Japan, anthropogenic CO from the North China Plain and from the Sichuan Basin prevailed in the northern and southern part of the WCB, while $\mathrm{CO}$ from biomass burning in Indochina was mostly distributed in the middle part of the WCB.

3. Topography in East Asia influences vertical transport of $\mathrm{CO}$ in different ways. In particular, topography-induced lee-side troughs east of the Hengduan Mountains over Indochina lead to strong convection. This new mechanism proposed by Lin et al. (2009) is supported by this study in explaining $\mathrm{CO}$ transport to the middle troposphere and further extended for $\mathrm{CO}$ transport to the upper troposphere. Strong convection from the Sichuan Basin also plays an important role in vertically transporting anthropogenic $\mathrm{CO}$. The topography interacting with frontal activities can enhance the vertical transport of CO substantially in the North China Plain.

4. Extratropical cyclones and associated frontal activities are important mechanism in lifting $\mathrm{CO}$ from the boundary layer to the free troposphere, as illustrated by the three cases and earlier studies. East Asia is one of two regions between 25 and $45^{\circ} \mathrm{N}$ with most frequent WCB events (Eckhardt et al., 2004). Inside East Asia, there are two regions where cyclones occur most frequently: one over the lee sides of the Altai-Sayan and the other in the East China Sea and the Sea of Japan, occurring mostly in spring and summer over both regions (Chen et al., 1991). The seasons and locations of the three high CO episodes just match well with these two areas and active cyclone seasons, which may not happen by chance.

5. Biomass burning is identified as an important source for all three episodes, suggesting that $\mathrm{CO}$ from sporadic fire activities can provide additional $\mathrm{CO}$ to less varying anthropogenic emission and enhance chances of high $\mathrm{CO}$ episodes. The fire regions shown in this study are the places with dense vegetation covers and with the most active forest fires in East Asia.

6. The MOPITT's vertical sensitivity is found to be enhanced in its new V5 NIR/TIR data in the free troposphere, even in the upper troposphere. The daytime 
V5 data can detect synoptic disturbances of weather systems on horizontal variation of $\mathrm{CO}$. The data also show more vertical structure than earlier versions and can distinguish $\mathrm{CO}$ enhancements at different layers of the troposphere, although the detected high CO is over a broad range in altitudes and lacks detailed vertical structure in comparison with the aircraft observations. Because the CO retrieval at a certain pressure level is often smoothed by the MOPITT averaging kernels, the MOPITT retrievals usually underestimate elevated $\mathrm{CO}$ at altitudes with peak $\mathrm{CO}$ plumes. The complication of clouds within frontal systems can generate large gaps in MOPITT data and cause underestimation of $\mathrm{CO}$ statistically in these regions. Nevertheless, MOPITT data can be used to qualitatively help diagnose vertical transport processes, with caution on their absolute $\mathrm{CO}$ values. On average, MOPITT slightly overestimates the background $\mathrm{CO}$ in the upper troposphere.

Acknowledgements. The authors gratefully acknowledge the following data and modeling tools. The satellite $\mathrm{CO}$ data are provided by the MOPITT team and acquired from the NASA Langley Research Center Atmospheric Science Data Center. The MOZAIC $\mathrm{CO}$ data are from the European Commission, Airbus, and the Airlines (Lufthansa, Austrian, Air France) who have carried free of charge the MOZAIC equipment and perform the maintenance since 1994. The final Analysis Data (FNL) were obtained from NOAA CDC. The GEOE-Chem model is developed and managed by the Atmospheric Chemistry Modeling Group at Harvard University with support from the NASA Atmospheric Chemistry Modeling and Analysis Program (ACMAP). The FLEXPART model development team consists of Andreas Stohl, Sabine Eckhardt, Harald Sodemann, and John Burkhart at the Norwegian Institute for Air Research (NILU). Insights and critiques from two anonymous reviewers are highly appreciated. Financial support is provided by an open fund from the Institute of Remote Sensing and Digital Earth, Chinese Academy of Sciences (OFSLRSS201107), the Key Basic Research Program (2010CB950704, 2014CB441203), and the Natural Science Foundation of China (41375140).

Edited by: T. Röckmann

\section{References}

Banic, C. M., Isaac, G. A., Cho, H. R., and Iribane, J. V.: The distribution of pollutants near a frontal surface: a comparison between field experiment and modeling, Water Air Soil Poll., 30, 171177, 1986.

Barret, B., Le Flochmoen, E., Sauvage, B., Pavelin, E., Matricardi, M., and Cammas, J. P.: The detection of post-monsoon tropospheric ozone variability over south Asia using IASI data, Atmos. Chem. Phys., 11, 9533-9548, doi:10.5194/acp-11-95332011, 2011.

Berntsen, T. K., Karlsdóttir, S., and Jaffe, D. A.: Influence of Asian emissions on the composition of air reaching the north western United States, Geophys. Res. Lett., 26, 2171-2174, doi:10.1029/1999GL900477, 1999.

Bertschi, I. B., Jaffe, D. A., Jaeglé, L., Price, H. U., and Dennison, J. B.: PHOBEA/ITCT 2002 airborne observations of trans-Pacific transport of ozone, CO, VOCs and aerosols to the northeast Pacific: impacts of Asian anthropogenic and Siberian Boreal fire emissions, J. Geophys. Res., 109, D23S12, doi:10.1029/2003JD004328, 2004.

Bethan, S., Vaughan, G., Gerbig, C., Volz-Thoms, A., Richer, H., and Tiddeman, D. A.: Chemical air mass differences near fronts, J. Geophys. Res., 103, 13413-13434, 1998.

Bey, I., Jacob, D. J., Yantosca, R. M., Logan, J. A., Field, B. D., Fiore, A. M., Li, Q., Liu, H. Y., Mickley, L. J., and Schultz, M. G.: Global modeling of tropospheric chemistry with assimilated meteorology: model description and evaluation, J. Geophys. Res., 106, 23073-23095, 2001.

Brown, R. M., Daum, P. H., Schwartz, S. E., and Hjelmfelt, M. R.: Variations in the chemical composition of clouds during frontal passage, in: The Meteorology of Acid Deposition, edited by: Samson, P. J., Air Pollut. Control Assoc., Pittsburgh, Pa., 202212, 1984.

Chan, D., Yuen, C. W., Higuchi, K., Shashkov, A., Liu, J., Chen, J., and Worthy, D.: On the $\mathrm{CO}_{2}$ exchange between the atmosphere and the biosphere: the role of synoptic and mesoscale processes, Tellus B, 56, 194-212, 2004.

Chen, B., Xu, X. D., Yang, S., and Zhao, T. L.: Climatological perspectives of air transport from atmospheric boundary layer to tropopause layer over Asian monsoon regions during boreal summer inferred from Lagrangian approach, Atmos. Chem. Phys., 12, 5827-5839, doi:10.5194/acp-12-5827-2012, 2012.

Chen, S., Kuo, Y., Zhong, P., and Bai, Q.: Synoptic climatology of cyclogenesis over East Asia, 1958-1987, Mon. Weather Rev., 119, 1407-1418, 1991.

Chung, K. K., Chan, J. C. L., Ng, C. N., Lam, K. S., and Wang, T.: Synoptic conditions associated with high carbon monoxide episodes at coastal station in Hong Kong, Atmos. Environ., 33, 3099-3095, 1999.

Cooper, O. R., Moody, J. L., Parrish, D. D., Trainer, M., Ryerson, T. B., Holloway, J. S., Hübler, G., Fehsenfeld, F. C., and Evans, M. J.: Trace gas composition of midlatitude cyclones over the western North Atlantic Ocean: a conceptual model, J. Geophys. Res., 107, 4056, doi:10.1029/2001JD000901, 2002.

Cooper, O. R., Forster, C., Parrish, D., Dunlea, E., Habler, G., Fehsenfeld, F., Holloway, J., Oltmans, S., Johnson, B., Wimmers, A., and Horowitz, L.: On the life-cycle of a stratospheric intrusion and its dispersion into polluted warm conveyor belts, J. Geophys. Res., 109, D23S09, doi:10.1029/2003JD004006, 2004.

Cooper, O. R., Stohl, A., Hubler, G., Hsie, E. Y., Parrish, D. D., Tuck, A. F., Kiladis, G. N., Oltmans, S. J., Johnson, B. J., Shapiro, M., Moody, J. L., and Lefohn, A. S.: Direct transport of midlatitude stratospheric ozone into the lower troposphere and marine boundary layer of the tropical Pacific Ocean, J. Geophys. Res., 110, D23310, doi:10.1029/2005JD005783, 2005.

Cooper, O. R., Stohl, A., Trainer, M., Thompson, A., Witte, J. C., Oltmans, S. J., Johnson, B. J., Merrill, J., Moody, J. L., Tarasick, D., Nédélec, P., Forbes, G., Newchurch, M. J., Schmidlin, F. J., Johnson, B. J., Turquety, S., Baughcum, S. L., Ren, X., Fehsenfeld, F. C., Meagher, J. F., Spichtinger, N., Brown, C. C., McKeen, S. A., McDermid, I. S., and Leblanc, T.: Large up- 
per tropospheric ozone enhancements above mid-latitude North America during summer: in situ evidence from the IONS and MOZAIC ozone monitoring network, J. Geophys. Res., 111, D24S05, doi:10.1029/2006JD007306, 2006.

Cristofanelli, P., Bonasoni, P., Collins, W., Feichter, J., Forster, C., James, P., Kentarchos, A., Kubik, P. W., Land, C., Meloen, J., Roelofs, G. J., Siegmund, P., Sprenger, M., Schnabel, C., Stohl, A., Tobler, L., Tositti, L., Trickl, T., and Zanis, P.: Stratosphere-to-troposphere transport: a model and method evaluation, STACCATO special section of J. Geophys. Res., 108, 8525, doi:10.1029/2002JD002600, 2003.

Daley, R.: Atmospheric Data Analysis, Cambridge University Press, Cambridge, 454 pp., 1991.

Damoah, R., Spichtinger, N., Forster, C., James, P., Mattis, I., Wandinger, U., Beirle, S., Wagner, T., and Stohl, A.: Around the world in 17 days - hemispheric-scale transport of forest fire smoke from Russia in May 2003, Atmos. Chem. Phys., 4, 13111321, doi:10.5194/acp-4-1311-2004, 2004.

Davies, D. K., Ilavajhala, S., Wong, M. M., and Justice, C. O.: Fire information for resource management system: archiving and distributing MODIS active fire data, IEEE T. Geosci. Remote, 47, 72-79, 2009.

Deeter, M. N., Emmons, L. K., Francis, G. L., Edwards, D. P., Gille, J. C., Warner, J. X., Khattatov, B., Ziskin, D., Lamarque, J.-F., Ho, S.-P., Yudin, V., Attié, J.-L., Packman, D., Chen, J., Mao, D., and Drummond, J. R.: Operational carbon monoxide retrieval algorithm and selected results for the MOPITT instrument, J. Geophys. Res., 108, 4399, doi:10.1029/2002JD003186, 2003.

Deeter, M. N., Emmons, L. K., Edwards, D. P., Gille, J. C., and Drummond, J. R.: Vertical resolution and information content of CO profiles retrieved by MOPITT, Geophys. Res. Lett., 31, L15112, doi:10.1029/2004GL020235, 2004.

Deeter, M. N., Worden, H. M., Edwards, D. P., Gille, J. C., and Andrews, A. E.: Evaluation of MOPITT retrievals of lowertropospheric carbon monoxide over the United States, J. Geophys. Res., 117, D13306, doi:10.1029/2012JD017553, 2012.

Deeter, M. N., Martínez-Alonso, S., Edwards, D. P., Emmons, L. K., Gille, J. C., Worden, H. M., Pittman, J. V., Daube, B. C., and Wofsy, S. C.: Validation of MOPITT Version 5 thermalinfrared, near-infrared, and multispectral carbon monoxide profile retrievals for 2000-2011, J. Geophys. Res., 118, 6710-6725, doi:10.1002/jgrd.50272, 2013.

Dickerson, R. R., Huffman, G. J., Luke, W. T., Nunnermacker, L. J., Pickering, K. E., Leslie, A. C. D., Lindsey, C. G., Slinn, W. G. N., Kelly, T. J., Daum, P. H., Delany, A. C., Greenberg, J. P., Zimmerman, P. R., Boatman, J. F., Ray, J. D., and Stedman, D. H.: Thunderstorms - an important mechanism in the transport of air pollutants, Science, 235, 4787, 460-464, 1987.

Dickerson, R. R., Li, C., Li, Z., Marufu, L., T., Stehr, J. W., McClure, B., Krotkov, N., Chen, H., Wang, P., Xia, X., Ban, X., Gong, F., Yuan, J., and Yang, J.: Aircraft observations of dust and pollutants over northeast China: insight into the meteorological mechanisms of transport, J. Geophys. Res., 112, D24S90, doi:10.1029/2007JD008999, 2007.

Ding, A., Wang, T., Xue, L., Gao, J., Stohl, A., Lei, H., Jin, D., Ren, Y., Wang, X., Wei, X., Qi, Y., Liu, J., and Zhang, X.: Transport of north China air pollution by midlatitude cyclones: case study of aircraft measurements in summer 2007, J. Geophys. Res., 114, D08304, doi:10.1029/2008JD011023, 2009.
Donnell, E. A., Fish, D. J., Dicks, E. M., and Thorpe, A. J.: Mechanisms for pollutant transport between the boundary layer and the free troposphere, J. Geophys. Res., 106, 7847-7856, 2001.

Drummond, J. R. and Mand, G. S.: The measurements of pollution in the troposphere (MOPITT) instrument: overall performance and calibration requirements, J. Atmos. Ocean. Tech., 13, 314320, 1996.

Drummond, J. R.: Measurements of pollution in the troposphere (MOPITT), in: The Use of EOS for Studies of Atmospheric Physics, edited by: Gille, J. C. and Visconti, G., the Netherlands, New York, 77-101, 1992.

Duncan, B. N., Martin, R. V., Staudt, A. C., Yevich, R., and Logan, J. A.: Interannual and seasonal variability of biomass burning emissions constrained by satellite observations, J. Geophys. Res., 108, 4040, doi:10.1029/2002JD002378, 2003.

Duncan, B. N., Logan, J. A., Bey, I., Megretskaia, I. A., Yantosca, R. M., Novelli, P. C., Jones, N. B., and Rinsland, C. P.: Global budget of CO, 1988-1997: source estimates and validation with a global model, J. Geophys. Res., 112, D22301, doi:10.1029/2007JD008459, 2007.

Eckhardt, S., Stohl, A., Wernli, H., James, P., Forster, C., and Spichtinger, N.: A 15-Year climatology of warm conveyor belts, J. Climate, 17, 218-237, 2004.

Edwards, D. P., Halvorson, C. M., and Gille, J. C.: Radiative transfer modeling for the EOS Terra satellite measurements of pollution in the troposphere (MOPITT instrument), J. Geophys. Res., 104, 16755-16775, 1999.

Emmons, L. K., Deeter, M. N., Gille, J. C., Edwards, D. P., Attie, J.-L., Warner, J., Ziskin, D., Khattatov, B., Yudin, V., Lamarque, J.-F., Ho, S.-P., Mao, D., Chen, J. S., Drummond, J., Novelli, P., Sachse, G., Coffey, M. T., Hannigan, J. W., Gerbig, C., Kawakami, S., Kondo, Y., Takegawa, N., Baehr, J., and Ziereis, H.: Validation of MOPITT CO retrievals with aircraft in situ profiles, J. Geophys. Res., 109, D03309, doi:10.1029/2003JD004101, 2004.

Giglio, L., Descloitres, J., Justice, C. O., and Kaufman, Y. J.: An enhanced contextual fire detection algorithm for MODIS, Remote Sens. Environ., 87, 273-282, 2003.

Hao, H., Valks, P., Loyola, D., Chen, Y. F., and Zimmer, W.: Spacebased measurements of air quality during the World Expo 2010 in Shanghai, Environ. Res. Lett., 6, 044004, doi:10.1088/17489326/6/4/044004, 2011.

He, H., Tarasick, D. W., Hocking, W. K., Carey-Smith, T. K., Rochon, Y., Zhang, J., Makar, P. A., Osman, M., Brook, J., Moran, M. D., Jones, D. B. A., Mihele, C., Wei, J. C., Osterman, G., Argall, P. S., McConnell, J., and Bourqui, M. S.: Transport analysis of ozone enhancement in Southern Ontario during BAQS-Met, Atmos. Chem. Phys., 11, 2569-2583, doi:10.5194/acp-11-25692011, 2011.

Heald, C. L., Jacob, D. J., Fiore, A. M., Emmons, L. K., Gille, J. C., Deeter, M. N., Warner, J., Edwards, D. P., Crawford, J. H., Hamlin, A. J., Sachse, G. W., Browell, E. V., Avery, M. A., Vay, S. A., Westberg, D. J., Blake, D. R., Singh, H. B., Sandholm, S. T., Talbot, R. W., and Fuelberg, H. E.: Asian outflow and transpacific transport of carbon monoxide and ozone pollution: an integrated satellite, aircraft and model perspective, J. Geophys. Res., 108, 4804, doi:10.1029/2003JD003507, 2003.

Hocking, W. K., Carey-Smith, T. K., Tarasick, D. W., Argall, P. S., Strong, K., Rochon, Y., Zawadzki, I., and Taylor, P. A.: Detection 
of stratospheric ozone intrusion by wind profiler radars, Nature, 450, 281-284, doi:10.1038/nature06312, 2007.

Holloway, T., Levy II, H., and Kasibhatla, P.: Global distribution of carbon monoxide, J. Geophys. Res., 105, 12123-12147, doi:10.1029/1999JD901173, 2000.

Jacob, D. J.: Introduction to Atmospheric Chemistry, Princeton University Press, Princeton, New Jersey, 1999.

Jacob, D. J., Crawford, J. H., Kleb, M. M., Connors, V. S., Bendura, R. J., Raper, J. L., Sachse, G. W., Gille, J. C., Emmons L., and Heald, C. L.: Transport and Chemical Evolution over the Pacific (TRACE-P) aircraft mission: design, execution, and first results, J. Geophys. Res., 108, 9000, doi:10.1029/2002JD003276, 2003.

Jaffe, D., Anderson, T., Covert, D., Kotchenruther, R., Trost, B., Danielson, J., Simpson, W., Berntsen, T., Karlsdottir, S., Blake, D., Harris, J., Carmichael, G., and Uno, I.: Transport of Asian air pollution to North America, Geophys. Res. Lett., 26, 711-714, 1999.

Jaffe, D., Bertschi, I., Jaegle, L., Novelli, P., Reid, J. S., Tanimoto, H., Vingarzan, R., and Westphal, D. L.: Long-range transport of Siberian biomass burning emissions and impact on surface ozone in western North America, Geophys. Res. Lett., 31, L16106, doi:10.1029/2004GL020093, 2004.

Jiang, Z., Jones, D. B. A., Kopacz, M., Liu, J., Henze, D. K., and Heald, C.: Quantifying the impact of model errors on top-down estimates of carbon monoxide emissions using satellite observations, J. Geophys. Res., 116, D15306, doi:10.1029/2010JD015282, 2011.

Jones, D. B. A., Bowman, K. W., Logan, J. A., Heald, C. L., Liu, J., Luo, M., Worden, J., and Drummond, J.: The zonal structure of tropical $\mathrm{O}_{3}$ and $\mathrm{CO}$ as observed by the Tropospheric Emission Spectrometer in November 2004 - Part 1: Inverse modeling of CO emissions, Atmos. Chem. Phys., 9, 3547-3562, doi:10.5194/acp-9-3547-2009, 2009.

Justice, C. O., Giglio, L., Korontzi, S., Owens, J., Morisette, J. T., Roy, D., Descloitres, J., Alleaume, S., Petitcolin, F., and Kaufman, Y.: The MODIS fire products, Remote Sens. Environ., 83, 244-262, 2002.

Kar, J., Bremer, H., Drummond, J. R., Rochon, Y. J., Jones, D. B. A., Nichitiu, F., Zou, J., Liu, J., Gille, J. C., Edwards, D. P., Deeter, M. N., Francis, G., Ziskin, D., and Warner, J.: Evidence of vertical transport of carbon monoxide from measurements of pollution in the troposphere (MOPITT). Geophys. Res. Lett., 31, L23105, doi:10.1029/2004GL021128, 2004.

Kar, J., Drummond, J. R., Jones, D. B. A., Liu, J., Nichitiu, F., Zou, J., Gille, J. C. Edwards, D. P., and Deeter, M. N.: Carbon monoxide $(\mathrm{CO})$ maximum over the Zagros mountains in the Middle East: signature of mountain venting?, Geophys. Res. Lett., 33, L15819, doi:10.1029/2006GL026231, 2006.

Kar, J., Jones, D. B. A., Drummond, J. R., Attie, J. L., Liu, J., Zou, J., Nichitiu, F., Seymour, M. D., Edwards, D. P., Deeter, M. N., Gille, J. C., and Richter, A.: Measurement of low-altitude CO over the Indian subcontinent by MOPITT, J. Geophys. Res., 113, D16307, doi:10.1029/2007JD009362, 2008.

Kopacz, M., Jacob, D. J., Fisher, J. A., Logan, J. A., Zhang, L., Megretskaia, I. A., Yantosca, R. M., Singh, K., Henze, D. K., Burrows, J. P., Buchwitz, M., Khlystova, I., McMillan, W. W., Gille, J. C., Edwards, D. P., Eldering, A., Thouret, V., and Nedelec, P.: Global estimates of CO sources with high resolution by adjoint inversion of multiple satellite datasets (MOPITT,
AIRS, SCIAMACHY, TES), Atmos. Chem. Phys., 10, 855-876, doi:10.5194/acp-10-855-2010, 2010.

Kowol-Santen, J., Beekmann, M., Schmitgen, S., and Dewey, K.: Tracer analysis of transport from the boundary layer to the free atmosphere, Geophys. Res. Lett., 28, 2907-2910, 2001.

Lavoué, D., Liousse, C., Cachier, H., Stocks, B. J., and Goldammer, J. G.: Modeling of carbonaceous particles emitted by boreal and temperate wildfires at northern latitudes, J. Geophys. Res., 105, 26871-26890, doi:10.1029/2000JD900180, 2000.

Lawrence, M. G., Rasch, P. J., von Kuhlmann, R., Williams, J., Fischer, H., de Reus, M., Lelieveld, J., Crutzen, P. J., Schultz, M., Stier, P., Huntrieser, H., Heland, J., Stohl, A., Forster, C., Elbern, H., Jakobs, H., and Dickerson, R. R.: Global chemical weather forecasts for field campaign planning: predictions and observations of large-scale features during MINOS, CONTRACE, and INDOEX, Atmos. Chem. Phys., 3, 267-289, doi:10.5194/acp-3267-2003, 2003.

Li, Q. B., Jacob, D. J., Park, R. J., Wang, Y. X., Heald, C. L., Hudman, R., Yantosca, R. M., Martin, R. V., and Evans, M. J.: North American pollution outflow and the trapping of convectively lifted pollution by upper-level anticyclone, J. Geophys. Res., 110, D10301, doi:10.1029/2004JD005039, 2005.

Li, Z., Chen, H., Cribb, M., Dickerson, R., Holben, B., Li, C., Lu, D., Luo, Y., Maring, H., Shi, G., Tsay, S.-C., Wang, P., Wang, Y., Xia, X., Zheng, Y., Yuan, T., and Zhao, F.: Preface to special section on East Asian Studies of Tropospheric Aerosols: an International Regional Experiment (EAST-AIRE), J. Geophys. Res., 112, D22S00, doi:10.1029/2007JD008853, 2007.

Liang, Q., Jaegle, L., Jaffe, D. A., Weiss-Penzias, P., Heckman, A., and Snow, J. A.: Long-range transport of Asian pollution to the northeast Pacific: seasonal variations and transport pathways of carbon monoxide, J. Geophys. Res., 109, D23S07, doi:10.1029/2003JD004402, 2004.

Lin, C.-Y., Hsu, H.-M., Lee, Y. H., Kuo, C. H., Sheng, Y.-F., and Chu, D. A.: A new transport mechanism of biomass burning from Indochina as identified by modeling studies, Atmos. Chem. Phys., 9, 7901-7911, doi:10.5194/acp-9-7901-2009, 2009.

Liu, C., Beirle, S., Butler, T., Liu, J., Hoor, P., Jöckel, P., Penning de Vries, M., Pozzer, A., Frankenberg, C., Lawrence, M. G., Lelieveld, J., Platt, U., and Wagner, T.: Application of SCIAMACHY and MOPITT CO total column measurements to evaluate model results over biomass burning regions and Eastern China, Atmos. Chem. Phys., 11, 6083-6114, doi:10.5194/acp11-6083-2011, 2011.

Liu, H. Y., Jacob, D. J., Bey, I., Yantosca, R. M., Duncan, B. N., and Sachse, G. W.: Transport pathways for Asian combustion outflow over the Pacific: interannual and seasonal variations, J. Geophys. Res., 108, 8786, doi:10.1029/2002JD003102, 2003.

Liu, J., Drummond, J. R., Li, Q., Gille, J. C., and Ziskin, D. C.: Satellite mapping of $\mathrm{CO}$ emission from forest fires in northwest America using MOPITT measurements, Remote Sens. Environ., 95, 502-516, 2005.

Liu, J., Drummond, J. R., Jones, D. B. A., Cao, Z., Bremer, H., Kar, J., Zou, J., Nichitiu, F., and Gille, J. C.: Large horizontal gradients in atmospheric $\mathrm{CO}$ at the synoptic scale as seen by spaceborne measurements of pollution in the troposphere, J. Geophys. Res., 111, D02306, doi:10.1029/2005JD006076, 2006.

Mari, C., Evans, M. J., Palmer, P. I., Jacob, D. J., and Sachse, G. W.: Export of Asian pollution during two cold front episodes 
of the TRACE-P experiment, J. Geophys. Res., 109, D15S17, doi:10.1029/2003JD004307, 2004.

Miyazaki, Y., Kondo, Y., Koike, M., Fuelberg, H. E., Kiley, C. M., Kita, K., Takegawa, N., Sachse, G. W., Flocke, F., Weinheimer, A. J., Singh, H. B., Eisele, F. L., Zondlo, M., Talbot, R. W., Sandholm, S. T., Avery, M. A., and Blake, D. R.: Synoptic-scale transport of reactive nitrogen over the western Pacific in spring, J. Geophys. Res., 108, 8788, doi:10.1029/2002JD003248,2003.

Marenco, A., Thouret, V., Nédélec, P., Smit, H., Helten, M., Kley, D., Karcher, F., Simon, P., Law, K., Pyle, J., Poschmann, G., Wrede, R. V., Hume, C., and Cook, T: Measurement of ozone and water vapor by Airbus in-service aircraft: the MOZAIC airborne program, An overview, J. Geophys. Res., 103, 25631-25642, 1998.

Nassar, R., Logan, J. A., Megretskaia, I. A., Murray, L. T., Zhang, L., and Jones, D. B. A.: Analysis of tropical tropospheric ozone, carbon monoxide, and water vapor during the 2006 El Niño using TES observations and the GEOS-Chem model, J. Geophys. Res., 114, D17304, doi:10.1029/2009JD011760, 2009.

Nassar, R., Jones, D. B. A., Suntharalingam, P., Chen, J. M., Andres, R. J., Wecht, K. J., Yantosca, R. M., Kulawik, S. S., Bowman, K. W., Worden, J. R., Machida, T., and Matsueda, H.: Modeling global atmospheric $\mathrm{CO}_{2}$ with improved emission inventories and $\mathrm{CO}_{2}$ production from the oxidation of other carbon species, Geosci. Model Dev., 3, 689-716, doi:10.5194/gmd-3-689-2010, 2010.

Nédélec, P., Thpuret, V., Brioude, J., Sauvage, B., Cammas, J., Stohl, A.: Extreme CO concentrations in the upper troposphere over northeast Asia in June 2003 from the in situ MOZAIC aircraft data, Geophys. Res. Lett., 32, L14807, doi:10.1029/2005GL023141, 2005.

Novelli, P., Masarie, K. A., and Lang, P. M.: Distributions and recent changes of carbon monoxide in the lower troposphere, J. Geophys. Res., 103, 19015-19033, 1998.

Olivier, J. G. J. and Berdowski, J. J. M.: Global emission sources and sinks, in: The Climate System, edited by: Berdowski, J., Guicherit, R., and Heij, B. J., Swets \& Zeitlinger, Lisse, the Netherlands, 33-77, 2001.

Oltmans, S. J., Lefohn, A. S., Harris, J. M., Tarasick, D. W., Thompson, A. M., Wernli, H., Johnson, B. J., Novelli, P. C., Montzka, S. A., Ray, J. D., Patrick, L. C., Sweeney, C., Jefferson, A., Dann, T., Davies, J., Shapiro, M., and Holben, B. N.: Enhanced ozone over western North America from biomass burning in Eurasia during April 2008 as seen in surface and profile observations, Atmos. Environ., 44, 4497-4509, 2010.

Pan, L., Gille, J. C., Edwards, D. P., Bailey, P. L., and Rodgers, C. D.: Retrieval of tropospheric carbon monoxide for the MOPITT experiment, J. Geophys. Res., 103, 32277-32290, 1998.

Pickering, K. E., Dickerson, R. R., Huffman, G. J., Boatman, J. F., and Schanot, A.: Trace gas transport in the vicinity of frontal convective clouds, J. Geophys. Res., 93, 759-773, doi:10.1029/JD093iD01p00759, 1998.

Randel, W. J., Park, M., Emmons, L., Kinnison, D., Bernath, P., Walker, K. A., Boone, C., and Pumphrey, H.: Asian monsoon transport of pollution to the stratosphere, Science, 328, 611-613, doi:10.1126/science.1182274, 2010.

Rogers, C. D.: Inverse Methods for Atmospheric Sounding, Theory and Practice, World Sci., 234 pp., River Edge, NJ, 2000.
Schultz, M. G.: On the use of ATSR fire count data to estimate the seasonal and interannual variability of vegetation fire emissions, Atmos. Chem. Phys., 2, 387-395, doi:10.5194/acp-2-387-2002, 2002.

Stohl, A.: A 1-year Lagrangian "climatology" of airstreams in the North Hemisphere troposphere and lowermost stratosphere, J. Geophys. Res., 106, 7263-7279, 2001.

Stohl, A., Hittenberger, M., and Wotawa, G.: Validation of the Lagrangian particle dispersion model FLEXPART against large scale tracer experiment data, Atmos. Environ., 24, 4245-4264, 1998.

Stohl, A., Eckhardt, S., Forster, C., James, P., and Spichtinger, N.: On the pathways and timescales of intercontinental air pollution transport, J. Geophys. Res., 107, 4684, doi:10.1029/2001JD001396, 2002.

Stohl, A., Forster, C., Frank, A., Seibert, P., and Wotawa, G.: Technical note: The Lagrangian particle dispersion model FLEXPART version 6.2, Atmos. Chem. Phys., 5, 2461-2474, doi:10.5194/acp-5-2461-2005, 2005.

Streets, D. G., Zhang, Q., Wang, L., He, K., Hao, J., Wu, Y., Tang, Y., and Carmichael, G. R.: Revisiting China's CO emissions after the Transport and Chemical Evolution over the Pacific (TRACE-P) mission: synthesis of inventories, atmospheric modeling, and observations, J. Geophys. Res., 111, D14306, doi:10.1029/2006JD007118, 2006.

Su, M., Lin, Y., Fan, X., Peng, L., Zhao, C.: Impacts of global emissions of $\mathrm{CO}, \mathrm{NO}_{\mathrm{X}}$, and $\mathrm{CH}_{4}$ on China tropospheric hydroxyl free radicals, Adv. Atmos. Sci., 29, 838-854, 2012.

Suntharalingam, P., Jacob, D. J., Palmer, P. I., Logan, J. A., Yantosca, R. M., Xiao, Y., Evans, M. J., Streets, D., Vay, S. A., and Sachse, G.: Improved quantification of Chinese carbon fluxes using $\mathrm{CO}_{2} / \mathrm{CO}$ correlations in Asian outflow, J. Geophys. Res., 109, D18S18, doi:10.1029/2003JD004362, 2004.

Tao, S. and Ding, Y.: Observational evidence of the influence of the Qinghai-Xizang (Tibet) Plateau on the occurrence of heavy rain and severe convective storms in China, B. Am. Meteorol. Soc., 62, 2-30, 1981.

Tanimoto, H., Sawa, Y., Yonemura, S., Yumimoto, K., Matsueda, H., Uno, I., Hayasaka, T., Mukai, H., Tohjima, Y., Tsuboi, K., and Zhang, L.: Diagnosing recent CO emissions and ozone evolution in East Asia using coordinated surface observations, adjoint inverse modeling, and MOPITT satellite data, Atmos. Chem. Phys., 8, 3867-3880, doi:10.5194/acp-8-3867-2008, 2008.

Tsutsumi, Y., Makino, Y., and Jensen, J. B.: Vertical and latitudinal distributions of tropospheric ozone over the western Pacific: case studies from the PACE aircraft missions, J. Geophys. Res., 108, 4251, doi:10.1029/2001JD001374, 2003.

van der Werf, G. R., Randerson, J. T., Giglio, L., Collatz, G. J., Mu, M., Kasibhatla, P. S., Morton, D. C., DeFries, R. S., Jin, Y., and van Leeuwen, T. T.: Global fire emissions and the contribution of deforestation, savanna, forest, agricultural, and peat fires (19972009), Atmos. Chem. Phys., 10, 11707-11735, doi:10.5194/acp10-11707-2010, 2010.

Wang, T., Nie, W., Gao, J., Xue, L. K., Gao, X. M., Wang, X. F., Qiu, J., Poon, C. N., Meinardi, S., Blake, D., Wang, S. L., Ding, A. J., Chai, F. H., Zhang, Q. Z., and Wang, W. X.: Air quality during the 2008 Beijing Olympics: secondary pollutants and regional impact, Atmos. Chem. Phys., 10, 7603-7615, doi:10.5194/acp10-7603-2010, 2010. 
Wang, X. L., Feng, Y., Compo, G. P., Swail, V. R., Zwiers, F. W., Allan, R. J., and Sardeshmukh, P. D.: Trends and low frequency variability of extra-tropical cyclone activity in the ensemble of twentieth century reanalysis, Clim. Dynam., 40, 27752800, doi:10.1007/s00382-012-1450-9, 2013.

Wofsy, S. C. and the HIPPO Science Team and Cooperating Modellers and Satellite Teams: HIAPER pole-to-pole observations (HIPPO): Fine-grained, global-scale measurements of climatically important atmospheric gases and aerosols, Phil. Trans. R. Soc. A, 369, 2073-2086, doi:10.1098/rsta.2010.0313, 2011.

Worden, H. M., Deeter, M. N., Edwards, D. P., Gille, J. C., Drummond, J. R., and Nédélec, P.: Observations of near-surface carbon monoxide from space using MOPITT multispectral retrievals, J. Geophys. Res., 115, D18314, doi:10.1029/2010JD014242, 2010.

Wotawa, G., Novelli, P. C., Trainer, M., and Granier, C.: Interannual variability of summertime $\mathrm{CO}$ concentrations in the Northern Hemisphere explained by boreal forest fires in North America and Russia, Geophys. Res. Lett., 28, 4575-4578, 2001.

Yienger, J. J., Galanter, M., Holloway, T. A., Phadnis, M. J., Guttikunda, S. K., Carmichael, G. R., Moxim, W. J., and Levy II, H.: The episodic nature of air pollution transport from Asia to North America, J. Geophys. Res., 105, 26931-26945, doi:10.1029/2000JD900309, 2000.

Yu, R., Xu, Y., Zhou, T., and Li, J.: Relation between rainfall duration and diurnal variation in the warm season precipitation over central eastern China, Geophys. Res. Lett., 34, Li3703, doi:10.1029/2007GL030315, 2007.

Yue, X. and Wang, H.: The springtime North Asia cyclone activity index and the Southern Annular Mode, Adv. Atmos. Sci., 25, 673-679, 2008.
Yurganov, L. N., McMillan, W. W., Dzhola, A. V., Grechko, E. I., Jones, N. B., and van derWerf, G.: Global AIRS and MOPITT CO measurements: validation, comparison, and links to biomass burning variations and carbon cycle, J. Geophys. Res., 113, D09301, doi:10.1029/2007JD009229, 2008.

Zhang, L., Jacob, D. J., Bowman, K. W., Logan, J. A., Turquety, S., Hudman, R. C., Li, Q. B., Beer, R., Worden, H. M., Worden, J. R., Rinsland, C. P., Kulawik, S. S., Lampel, M. C., Shephard, M. W., Fisher, B. M., Eldering, A., and Avery, M. A.: Ozone$\mathrm{CO}$ correlations determined by the TES satellite instrument in continental outflow regions, Geophys. Res. Lett., 33, L18804, doi:10.1029/2006GL026399, 2006.

Zhang, Q., Streets, D. G., Carmichael, G. R., He, K. B., Huo, H., Kannari, A., Klimont, Z., Park, I. S., Reddy, S., Fu, J. S., Chen, D., Duan, L., Lei, Y., Wang, L. T., and Yao, Z. L.: Asian emissions in 2006 for the NASA INTEX-B mission, Atmos. Chem. Phys., 9, 5131-5153, doi:10.5194/acp-9-5131-2009, 2009.

Zhao, C., Wang, W., Yang, Y., Fu, R., Cunnold, D., and Choi, Y.: Impact of East Asian summer monsoon on the air quality over China: view from space, J. Geophys. Res., 115, D09301, doi:10.1029/2009JD012745, 2010.

Zhao, T. L., Gong, S. L., Zhang, X. Y., and Jaffe, D. A.: Asian dust storm influence on North American ambient PM levels: observational evidence and controlling factors, Atmos. Chem. Phys., 8 , 2717-2728, doi:10.5194/acp-8-2717-2008, 2008.

Zhou, D., Ding, A., Mao, H., Fu, C., Wang, T., Chan, L. Y., Ding, K., Zhang, Y., Liu, J., Lu, A., and Hao, N.: Impacts of the East Asian monsoon on lower tropospheric ozone over coastal South China, Environ. Res. Lett., 8, 044011, doi:10.1088/17489326/8/4/044011, 2013. 